\title{
Monetary Policy in Sudden Stop-Prone Economies ${ }^{\dagger}$
}

\author{
Louphou Coulibaly* \\ Université de Montréal
}

This version: November 15, 2018

Latest version

\begin{abstract}
Monetary policy procyclicality is a pervasive feature of emerging market economies. In this paper, I propose a parsimonious theory explaining this fact in a model where access to foreign financing depends on the real exchange rate and the government lacks commitment. The discretionary monetary policy is procyclical to mitigate balance sheet effects originating from exchange rate depreciations during sudden stops. Committing to an inflation targeting regime is found to increase social welfare and reduce the frequency of financial crises, despite increasing their severity. Finally, the ability to use capital controls induces a less procyclical discretionary monetary policy and delivers higher welfare gains than an inflation targeting regime by reducing both the frequency and the severity of crises.
\end{abstract}

Keywords: Sudden stops; Monetary policy; Capital controls; Time-consistency; Pecuniary externality; Aggregate demand externality.

JEL Classifications: E44, E52, F38, F41, G01

${ }^{\dagger}$ I am greatly indebted to Julien Bengui and Javier Bianchi for their invaluable guidance. I am grateful to Anton Korinek and Baris Kaymak for their support. For useful suggestions and comments, I thank Manuel Amador, Anmol Bhandari, Reinhard Ellwanger, Jonathan Heathcote, Kyle Herkenhoff, Fabrizio Perri, seminar participants at the Bank of Canada, Federal Reserve Bank of Minneapolis, Midwest Macroeconomic Meetings, and other seminars and conferences. I thank members of workshops at the Université de Montréal and the University of Minnesota. I am grateful to the Federal Reserve Bank of Minneapolis and the Economics Department at the University of Virginia for their hospitality.

${ }^{*}$ Department of Economics. Address: C.P. 6128, succursale Centre-ville, Montréal, QC H3C 3J7, Canada. Phone: (514) 343-6111. Email: c.louphou@gmail.com 


\section{Introduction}

Countercyclical stabilization policy constitutes a central tenet of macroeconomics. Yet, unlike in advanced economies, monetary policy appears to be procyclical in many emerging markets, meaning that it is often expansionary in booms and contractionary in recessions (Kaminsky et al., 2004). In this paper, I propose a theory to explain this contrasting empirical regularity based on the premise that governments lack the ability to commit to future policies and that emerging markets economies frequently experience capital account reversals, often referred to as Sudden Stops (Calvo, 1998), associated with adverse balance sheet effects originating from real exchange rate depreciations.

In my model, in the midst of a Sudden Stop, the government is inclined to pursue a contractionary monetary policy to appreciate the real exchange rate and support the value of the collateral accepted by foreign lenders, in an effort to relax binding financial constraints faced by domestic agents. Ex ante, however, the expectation of such monetary policy interventions during Sudden Stops aggravates overborrowing problems. As a result, the government finds it attractive during tranquil times to pursue an expansionary monetary policy that shifts demand towards the non-tradable sector and away from tradable goods, so as to mitigate overborrowing by private agents. In contrast, absent credit frictions, the government would aim for a perfect stabilization of output and prices at all times, in line with the standard prescription of the New Keynesian literature.

In addition to offering a theory that explains monetary policy procyclicality in emerging markets, I conduct an evaluation of the performance of alternative policy regimes. This analysis suggests that the procyclical discretionary monetary policy regime is dominated by several alternative candidates. First, I find that, relative to the procyclical discretionary monetary regime, committing to an inflation targeting regime generates welfare gains and reduces the frequency of financial crises, despite increasing their severity. Second, I also find that absent commitment, the ability to resort to capital controls to deal with overborrowing reduces the degree of procyclicality of discretionary monetary policy, and brings welfare gains associated with a drop in both the frequency and severity of financial crises. My analysis thus supports the view that procyclical monetary policy, despite being optimal under discretion, may be costly for emerging market economies.

My model builds on the small open economy real model of Sudden Stops of Mendoza (2002), in which domestic households consume tradable and non-tradable goods, and face a borrowing constraint linked to the real exchange rate. In this model, Sudden Stops result from an adverse feedback loop between tightening credit constraints and real exchange rate depreciations following a sequence of bad shocks. It is well understood that this class of models feature 
overborrowing, as private agents fail to internalize their contribution to systemic risk stemming from the influence of current borrowing decisions on the economy's future borrowing capacity via the real exchange rate (Korinek, 2009, Bianchi, 2011). To study monetary policy in this environment, I introduce monopolistically competitive firms and nominal rigidities in the non-tradable production sector.

I start by studying the optimal monetary policy problem of a government that cannot commit to future policies in an economy into which capital flows freely (i.e., in the absence of capital controls). The discretionary monetary policy in this environment can easily be related to the standard targeting rules developed in the New Keynesian literature (see Woodford, 2003). It expresses the path of the inflation rate as a function of a measure of the output gap (i.e., the labor wedge) and variables that account for the relevant financial conditions before and during financial crisis episodes.

This characterization of the discretionary monetary policy highlights the role of financial frictions in the design of monetary policy. In the absence of credit frictions, a price stability policy is always optimal. This finding is in line with the standard result in the New Keynesian literature suggesting that a policy that offsets distortion stemming from nominal rigidities is welfare-dominant when nominal rigidities and monopolistic competition are the only sources of frictions (see, e.g., Kollmann, 2002 and Schmitt-Grohé and Uribe, 2007). Credit frictions, however, create policy trade-offs between price stability and financial stability. The government only finds it optimal and time-consistent to follow a price stability policy in the knife-edge case where the inter-temporal elasticity of substitution is equal to the intra-temporal elasticity of substitution between tradable and non-tradable goods.

The manner in which financial conditions influence monetary policy crucially depends on the values of the elasticities of substitution. For standard values, the discretionary monetary policy involves a form of pro-cyclicality, being contractionary when a financial crisis occurs and expansionary ahead of a crisis. During financial crises, the real exchange rate falls and reduces significantly foreign borrowing capacity. Private agents, however, fail to internalize the general equilibrium benefits of a decrease in their demands for goods (i.e., an aggregate demand externality). A contractionary monetary policy reducing activity in the non-tradable sector serves to prevents too large a real exchange rate depreciation to sustain the value of collateral and tame balance sheet effects. Ahead of a potential crisis, private agents tend to overborrow because they fail to internalize how their private borrowing decisions affect the real exchange rate in the future, which in turn may lead to financial amplification and systemic risk during financial distress (i.e., a pecuniary externality). This overborrowing decision tends to make the real exchange rate overvalued from a financial fragility perspective. Generating a boom in the 
non-tradable sector reduces households' marginal propensity to consume the tradable good, discourages foreign borrowing and contains the rise in the current real exchange rate, which in turn mitigates future real exchange depreciations and prevents a large drops in borrowing capacity during future episodes of financial distress. This characterization helps account for the observation of Kaminsky et al. (2004) that monetary policy appears to be procyclical in emerging economies.

The availability of capital flow taxes modifies the features of the discretionary monetary policy. When capital flow taxes are used optimally, the conditions under which a price stability policy is desirable are less restrictive than when they cannot be used. Ahead of potential crises, capital inflow taxes are effective at correcting the pecuniary externality, and thus stabilizing prices is optimal. A policy trade-off between price stability and financial stability only arises during periods when the credit constraint is binding since capital controls are then of little help.

A quantitative analysis of the model delivers several results that contribute to the current discussion on the optimal design of monetary policy in emerging market economies, and the dilemma/trilemma debate in international finance (see, Farhi and Werning, 2014 and Rey, 2015). First, when capital controls cannot be used, relative to the discretionary monetary policy regime, there are substantial gains from committing over a simple targeting rule that stabilizes the producer price index, hereafter an inflation targeting regime. Such a commitment results in a lower unconditional probability of crises (4.3 percent versus 5.5 percent under the procyclical discretionary regime), but more severe crises (output drops by 29.7 percent versus 21.9 percent under the procyclical discretionary regime). Overall, committing to inflation targeting regime delivers welfare gains relative to the procyclical discretionary regime.

Second, capital controls are always useful under both an inflation targeting policy and the discretionary monetary policy. This is because capital controls prevent excessive risk exposure (see Bianchi, 2011; Jeanne and Korinek, 2012; Bianchi and Mendoza, 2018), which reduces the volatility of the external accounts. Moreover, when the government has access to capital controls, relative to an inflation targeting regime, the discretionary monetary policy regime, which is no longer procyclical during tranquil times, delivers larger welfare gains and reduces both the incidence of crises (1.1 percent versus 1.3 percent under an inflation targeting regime with capital controls) and the severity of crises (total output drops by 17.2 percent versus 17.8 percent under an inflation targeting regime with capital controls).

This paper is related to the literature on the design of monetary policy in economies with financial frictions. ${ }^{1}$ Christiano et al. (2004), Curdia (2007) Gertler et al. (2007) and Braggion

\footnotetext{
${ }^{1}$ An earlier literature compared the performance of different monetary regimes in an environment with financial market imperfections (see, e.g., Clarida et al., 2002; Céspedes et al., 2004 and Moron and Winkelried, 2005).
} 
et al. (2009) study monetary policy in times of crisis in frameworks where financial markets are incomplete and crises are unexpected one-shot events. Caballero and Krishnamurthy (2003), Aghion et al. (2004) and Benigno et al. (2011) examined the design of monetary policy in economies that last two or three periods and in which credit constraints become binding unexpectedly and remains binding afterwards. My contribution to this literature is to provide a characterization of the optimal monetary policy in normal times when financial crises are expected and endogenous.

Several other recent studies have explored monetary policy in dynamic environments featuring both nominal rigidities and financial frictions. Fornaro (2015) compares the performance of different monetary regimes and shows that a monetary regime that responds to financial conditions in times of crisis delivers higher welfare than an inflation targeting regime. In contrast, my main focus is on the analysis of discretionary monetary policy in the absence of capital controls. Ottonello (2015) studies exchange rate policy with optimal capital flow taxes in an economy featuring downward nominal wage rigidity and a collateral constraint. In the present paper, instead, the theoretical analysis mainly focus on the design of the optimal monetary policy in an environment in which the government does not have access to capital-controls and faces a time-inconsistency problem. Finally, Devereux et al. (2015) study optimal monetary and capital control policy in a related model where collateral constraints depend on the expected future value of assets and prudential capital flow management is never desirable, under flexible prices. In contrast, and in line with most of the literature, I consider a model where current prices matter for credit access and where, as a result, prudential capital flow management is generally beneficial.

This paper also relates to literature studying pecuniary externalities and inefficiencies resulting from the presence of market prices in borrowing constraints in real environments (see, e.g., Lorenzoni, 2008). Bianchi (2011), Korinek (2011) Benigno et al. (2013) and Bengui and Bianchi (2014) studied how this externality leads to overborrowing and showed to what extent capital control can restore constrained efficiency and reduce vulnerability to financial crises. Focusing on asset prices as a key factor driving debt dynamics and pecuniary externalities, Bianchi and Mendoza (2018) point out the time-inconsistency issues in macroprudential policies originating from the forward-looking nature of asset prices. Finally, my paper also relates to the work of Schmitt-Grohé and Uribe (2016), Farhi and Werning (2016) and Acharya and Bengui (2018) examining the use of taxes on financial transactions as a tool for managing aggregate demand in the presence of nominal rigidities and constraints on monetary policy. My paper draws upon to both strands of the literature and stands out by analyzing how monetary policy may be designed to simultaneously address both aggregate demand and pecuniary externalities. 
The remainder of the paper is organized as follows: Section 2 describes the analytical framework. Section 3 presents the optimal policy analysis. Section 4 conducts the quantitative analysis. Section 5 concludes, and is followed by an extended appendix.

\section{Model}

Consider a dynamic model of a small open economy. Households in this economy consume two goods (a tradable good and a non-tradable good) and can also engage in borrowing from foreign investors. The tradable good can be exchange with the rest of the world and the non-tradable good is consumed by domestic agents only.

\subsection{Households}

The economy is inhabited by a continuum of mass one of identical households with preferences described by:

$$
\mathbb{E}_{0} \sum_{t=0}^{\infty} \beta^{t} u\left(c_{t}, \ell_{t}\right)
$$

where $\beta \in(0,1)$ is a subjective discount factor, $\ell_{t}$ is labor supply and $c_{t}$ denotes consumption. The period utility function takes the standard constant relative-risk-aversion form, with a relative-risk-aversion coefficient $\sigma$. The consumption good is a composite of tradable consumption $c_{t}^{T}$ and non-tradable consumption $c_{t}^{N}$, according to an Armington-type CES aggregator:

$$
c_{t}=\left[a\left(c_{t}^{T}\right)^{-\eta}+(1-a)\left(c_{t}^{N}\right)^{-\eta}\right]^{-\frac{1}{\eta}}, \quad \eta>-1, a \in(0,1)
$$

The elasticity of substitution between tradable and non-tradable goods, which I will refer to as the intra-temporal elasticity, is $\gamma=1 /(\eta+1)$. Households receive a stochastic endowment of tradable goods $y_{t}^{T}$, profits $\Phi_{t}$ from the ownership of firms producing the non-tradable good, and labor income in each period $t$. Households can trade internationally with foreign investors in one period non state-contingent bonds denominated in units of the foreign currency. The bond pays an interest rate $R_{t}$, determined exogenously in the world market. The tradable endowment and the gross interest rate are the only sources of uncertainty, and the vector of shocks $s_{t} \equiv\left(y_{t}^{T}, R_{t}\right) \subseteq \mathbb{R}_{+}^{2}$ is assumed to follow a first-order Markov process. The sequential budget constraint of the household in terms of the domestic currency is given by:

$$
P_{t}^{T} c_{t}^{T}+P_{t}^{N} c_{t}^{N}+\frac{\mathcal{E}_{t} b_{t+1}}{R_{t}}=P_{t}^{T} y_{t}^{T}+W_{t} \ell_{t}+\Phi_{t}+\mathcal{E}_{t} b_{t}
$$


where $b_{t+1}$ denotes bond holdings that households choose at the beginning of time $t$. $\mathcal{E}_{t}$ is the nominal exchange rate defined as the price of the foreign currency in terms of the domestic currency. In terms of the domestic currency, $P_{t}^{T}$ is the nominal price of the tradable good, $P_{t}^{N}$ the nominal price of the non-tradable good and $W_{t}$ the nominal wage rate. The law of one price holds for the tradable good, which implies that $P_{t}^{T}=\mathcal{E}_{t} P_{t}^{T *}$ where $P^{T *}$ denotes the foreign currency price of the tradable good. For simplicity, the foreign-currency price of the tradable good is assumed to be constant and normalized to one. It follows that the domestic currency price of the tradable good is equal to the nominal exchange rate (i.e. $P_{t}^{T}=\mathcal{E}_{t}$ ).

Households' borrowing capacity denominated in units of tradables is limited by a fraction $\kappa$ of total income composed of tradable income and non-tradable income

$$
\frac{\mathcal{E}_{t} b_{t+1}}{R_{t}} \geq-\kappa\left[P_{t}^{T} y_{t}^{T}+W_{t} \ell_{t}+\Phi_{t}\right]
$$

This credit constraint captures balance sheet effects and financial amplification via exchange rate depreciations described as one of the main vulnerability of emerging market economies during financial crises (see Korinek, 2011). This formulation of the borrowing constraint was introduced by Mendoza (2002). One motivation for this formulation of the credit constraint is that it can result from institutional features of credit markets or financial-market frictions (such as monitoring costs, bankruptcy risk or imperfections in the judicial system) and captures the willingness of foreign lenders in such an environment to not allow borrowing beyond a certain limit tied to the borrower's income (see e.g., Bianchi, 2011 and Bianchi and Mendoza, 2018). ${ }^{2}$

The household's problem is to choose stochastic processes $\left\{c_{t}^{T}, c_{t}^{N}, b_{t+1}\right\}$ to maximize the expected utility (1) subject to (2)-(4), taking as given the sequence of prices, profits, exchange rates, stochastic tradable endowments and interest rates, as well as the initial debt level $b_{0}$. Letting $\lambda_{t} / P_{t}^{T}$ denotes the multiplier associated with the budget constraint (3) and $\mu_{t} / P_{t}^{T}$ the multiplier associated with the credit constraint (4), the household's optimal decision between tradable consumption and non-tradable consumption is given by:

$$
p_{t}^{N}=\frac{1-a}{a}\left(\frac{c_{t}^{T}}{c_{t}^{N}}\right)^{1 / \gamma}
$$

where $p_{t}^{N} \equiv P_{t}^{N} / \mathcal{E}_{t}$ denotes the relative price of non-tradables in terms of tradables. Similarly in what follows, $w_{t} \equiv W_{t} / \mathcal{E}_{t}$ represents the wage in terms of tradables and $\phi_{t} \equiv \Phi_{t} / \mathcal{E}_{t}$ is the firm profits in terms of tradables. The optimality condition (5) equates the marginal rate of substitution between the two goods, the tradable and the non-tradable, to their relative price.

\footnotetext{
${ }^{2}$ As shown by Bianchi and Mendoza (2018), the credit constraint depends on current prices (rather than future prices) when the possibility of default arises at the end of the current period.
} 
This condition describes the demand for the non-tradable good as a function of their relative price and the level of tradable absorption, and can be re-written as:

$$
c_{t}^{N}=\left[\frac{a}{1-a} p_{t}^{N}\right]^{-\gamma} c_{t}^{T} \equiv \alpha\left(p_{t}^{N}\right) c_{t}^{T} .
$$

Letting $u_{T}$ and $u_{N}$ denote the marginal utility of tradable consumption and non-tradable consumption respectively, the remaining household's first-order conditions are:

$$
\begin{aligned}
& \frac{-u_{\ell}(t)}{u_{N}(t)}=\underbrace{\left[1+\frac{\kappa \mu_{t}}{u_{T}(t)}\right]}_{z_{t}} \frac{w_{t}}{p_{t}^{N}} \\
& \lambda_{t}=u_{T}(t) \\
& \lambda_{t}=\beta R_{t} \mathbb{E}_{t} \lambda_{t+1}+\mu_{t} \\
& \mu_{t} \geq 0, \mu_{t}\left[b_{t+1}+\kappa\left(y_{t}^{T}+w_{t} \ell_{t}+\phi_{t}\right)\right]=0 .
\end{aligned}
$$

The optimality condition for labor supply (6) equates marginal cost in terms of non-tradable consumption from working one additional unit with the marginal benefit, which includes the relative wage $w_{t} / p_{t}^{N}$ and the relaxation effect on the credit constraint. The variable $z_{t}$ indicates the wage multiplier of an increase in labor supply. In particular, when the credit constraint binds, an increase of one unit of labor relaxes the constraint by $\kappa \mu_{t} \cdot w_{t}$, and the wage multiplier of this increase in labor is greater than $1\left(z_{t}>1\right)$. The Euler equation for debt $(8)$ states that the current shadow value of wealth equals the expected value of reallocating wealth to the next period plus an additional term that represents the shadow price of relaxing the credit constraint. Thus, conditions (6) and (8) show that the credit constraint introduces two distortions: an inter-temporal distortion arising from the presence of a credit constraint and an intra-temporal distortion that hinges on the wage income entering the credit constraint.

\subsection{Production Sector}

Non-tradable goods are supplied by firms, and denoted $y_{t}^{N}$. I introduce nominal rigidities in the non-tradable goods market by separating the sector into monopolistically competitive intermediate producers and perfectly competitive retailers. The non-tradable final good is produced by competitive firms that combine a continuum of non-tradable varieties indexed by $j \in[0,1]$ using the constant returns to scale CES technology

$$
y_{t}^{N}=\left(\int_{0}^{1} y_{j, t}^{N^{\frac{\varepsilon-1}{\varepsilon}}} d j\right)^{\frac{\varepsilon}{\varepsilon-1}}
$$


where $\varepsilon>1$ is the elasticity of substitution between any two varieties. Each variety $y_{j, t}^{N}$ is produced by a monopolistically competitive producer using labor $h_{j, t}$ according to a linear production function $y_{j, t}^{N}=A h_{j, t}$. These producers hire labor in a competitive market with wage $W_{t}$, but pays $\left(1-\tau^{h}\right) W_{t}$ net of a labor subsidy. Cost minimization implies that each firm faces the same real marginal cost (or unitary cost): $m c_{t}=\frac{1-\tau^{h}}{A} \frac{W_{t}}{P_{t}^{N}}$.

Price setting The intermediate goods firms face sticky price setting à la Rotemberg (1982). Accordingly, each firm $j$ faces a cost of adjusting prices which, when measured in terms of the final non-tradable good, is given by:

$$
\frac{\varphi}{2}\left(\frac{P_{j, t}^{N}}{P_{j, t-1}^{N}}-1\right)^{2} y_{t}^{N}
$$

where $\varphi$ is an adjustment cost parameter which determines the degree of nominal price rigidity and $P_{j, t}^{N}$ is the nominal price of variety $j$. Taking as given the sequence for $m c_{t}, y_{t}^{N}$ and $\mathcal{E}_{t}$, the monopolistically competitive firm $j$ optimally chooses the sequence of prices of its own variety, $P_{j, t}^{N}$, to maximize the stream of its expected discounted profit given by:

$$
\mathbb{E}_{0} \sum_{t=0}^{\infty} \Lambda_{0, t}\left[\left(\frac{P_{j, t}^{N}}{P_{t}^{N}}-m c_{t}\right) y_{j, t}^{N}-\frac{\varphi}{2}\left(\frac{P_{j, t}^{N}}{P_{j, t-1}^{N}}-1\right)^{2} y_{t}^{N}+T_{t}\right]
$$

where $\Lambda_{i, t+i} \equiv \beta^{t} u_{N}(t+i) / u_{N}(i)$ is the household's stochastic discount factor for the nontradable good between date $t$ and date $t+i$. $T_{t}$ represents the lump sum tax that firms pay to the government at date $t$. Each period, the intermediate goods firm faces a demand curve for its product arising from competitive final good firms' production function:

$$
y_{j, t}^{N}=\left(\frac{P_{j, t}^{N}}{P_{t}^{N}}\right)^{-\varepsilon} y_{t}^{N}
$$

In a symmetric equilibrium, all firms choose the same price $\left(P_{j, t}^{N}=P_{t}^{N}\right.$ for all $\left.j\right)$, and firms' optimal pricing rule is described by the following condition:

$$
\pi_{t}^{N}\left(1+\pi_{t}^{N}\right)=\frac{\varepsilon}{\varphi}\left[m c_{t}-\frac{\varepsilon-1}{\varepsilon}\right]+\mathbb{E}_{t} \Lambda_{t, t+1}\left[\frac{y_{t+1}^{N}}{y_{t}^{N}} \pi_{t+1}^{N}\left(1+\pi_{t+1}^{N}\right)\right]
$$

where $1+\pi_{t}^{N} \equiv P_{t}^{N} / P_{t-1}^{N}$ is the inflation rate of the non-tradable good. Condition (10) is the Rotemberg version of the non-linear New-Keynesian Phillips curve that relates the current inflation to the current deviation of marginal cost from marginal revenue and to the expected future inflation. It states that, given marginal costs, firms expecting higher inflation in the future 
would already raise prices in the current period to smooth out the necessary price adjustments over the time. According to this condition, firms would optimally set prices to equate the cost of adjusting prices today to a weighted average of current and future expected deviation of marginal cost from marginal revenue. Therefore, under full price flexibility (i.e. $\varphi=0$ ), firms would always set prices to equate marginal revenue to marginal cost. At the other extreme, when prices are fully rigid (i.e. $\varphi \rightarrow \infty$ ) firms would set prices once and for all to equate an average of current and future expected marginal revenues to an average of current and future expected marginal costs.

\subsection{Government}

The government (or central bank) in this economy sets the path of the nominal exchange rate as its monetary policy instrument. ${ }^{3}$ By controlling for the exchange-rate level $\mathcal{E}_{t}$, the government influences the relative price of non-tradables and is thus able to set the path for the inflation rate in the production sector, which can be seen as representing the government's monetary policy rule in this environment. To see more clearly how monetary policy operates, notice that any change in the relative price of non-tradables has an expenditure switching effect, and the demand for the non-tradable good is thus affected. This in turn requires a change in employment, which necessitates a change in the equilibrium wage through households' labor supply condition (6). Therefore, with its action on the exchange rate, the government affects firms' current marginal costs and thus their price-setting decisions. It then follows that by setting the level of the exchange rate, the government implicitly determines the path of the inflation rate.

The government also sets, once and for all, a constant labor subsidy $\tau^{h}$ which is financed through a lump sum tax on firms such that the government budget is balanced:

$$
\tau^{h} W_{t} h_{t}=T_{t}
$$

I set this constant labor subsidy to a level that would fully offset the monopoly distortion under flexible prices. This level is given by $\tau^{h}=1 / \varepsilon$.

\footnotetext{
${ }^{3}$ There exists a nominal domestic interest rate that would implement this policy. This interest rate can be found by introducing into the model a domestic bond that can be traded only among domestic households (its net supply is equal to zero in equilibrium). Then, given an equilibrium allocation, the Uncovered Interest Parity can be used to back out the nominal interest rate of domestic bond. This is the standard cashless approach (Woodford, 2003). Appendix B.1 provides further details.
} 


\subsection{Recursive Competitive Equilibrium}

Given a constant labor tax $\tau^{h}$ and an exchange rate path $\left\{\mathcal{E}_{t}\right\}_{t=0}^{\infty}$, a competitive equilibrium is defined by stochastic sequences of allocations $\left\{c_{t}^{T}, c_{t}^{N}, b_{t+1}, \ell_{t}, h_{t}\right\}_{t=0}^{\infty}$ and prices $\left\{P_{t}^{N}, W_{t}\right\}_{t=0}^{\infty}$ such that: $(a)$ agents maximize their lifetime utility (1) subject to the sequence of budget and credit constraints given by (3) and (4) for $t=0, \ldots, \infty$, taking as given $\left\{P_{t}^{N}, W_{t}\right\}_{t=0}^{\infty}$; (b) the markets for labor, non-tradable goods and tradable goods clear at each date $t$. The market clearing condition in the labor market, non-tradable goods market and tradable goods market are respectively given by

$$
\begin{gathered}
h_{t} \equiv \int_{0}^{1} h_{j, t} d j=\ell_{t} \\
y_{t}^{N}=c_{t}^{N}+\frac{\varphi}{2}\left(\pi_{t}^{N}\right)^{2} y_{t}^{N} \\
c_{t}^{T}+\frac{b_{t+1}}{R_{t}}=y_{t}^{T}+b_{t}
\end{gathered}
$$

I now turn to describing a competitive equilibrium in recursive form. The aggregate state vector of the economy is $(B, s)$ where $B$ is the aggregate bond holdings and $s$ is the exogenous shocks realization. The state variables for an household's optimization problem are the individual bond holdings $b$, and the aggregate state $(B, s)$. Denoting by $\Gamma(B, s)$ the perceived law of motion for aggregate bonds that households need to form expectations of future prices, and by $w(B, s)$ and $p^{N}(B, s)$ the respective pricing functions for labor and the non-tradable good, the optimization problem of households in recursive form is given by:

$$
\begin{aligned}
V(b, B, s) & =\max _{c^{T}, c^{N}, \ell, b^{\prime}} u\left(c\left(c^{T}, c^{N}\right), \ell\right)+\beta \mathbb{E}_{s^{\prime} \mid s} V\left(b^{\prime}, B^{\prime}, s^{\prime}\right) \\
\text { s.t. } \quad c^{T}+p^{N}(B, s) c^{N}+\frac{b^{\prime}}{R} & =y^{T}+w(B, s) \ell+\phi(B, s)+b \\
\frac{b^{\prime}}{R} & \geq-\kappa\left[y^{T}+w(B, s) \ell+\phi(B, s)\right] \\
B^{\prime} & =\Gamma(B, s)
\end{aligned}
$$

The solution to this problem yields decision rules for individual bond holdings $\hat{b}^{\prime}(b, B, s)$, labor supply $\hat{\ell}(b, B, s)$, tradable consumption $\hat{c}^{T}(b, B, s)$ and non-tradable consumption $\hat{c}^{N}(b, B, s)$. In a recursive rational expectations equilibrium, the law of motion for aggregate bonds must coincide with the actual law of motion for aggregate bonds induced by the decision rule for bond holdings, and given by $\hat{b}^{\prime}(B, B, s)$. The firm $j$ 's optimal pricing rule satisfies

$$
\left(1+\pi_{j}^{N}\right) \pi_{j}^{N}=\frac{\varepsilon-1}{\varphi}\left[\frac{1}{A} \frac{w(B, s)}{p^{N}(B, s)}-1\right]+\mathbb{E}_{s^{\prime} \mid s} \Lambda\left[\frac{\hat{h}^{\prime}\left(B^{\prime}, s^{\prime}\right)}{\hat{h}_{j}}\left(1+\pi^{N}\left(B^{\prime}, s^{\prime}\right)\right) \pi^{N}\left(B^{\prime}, s^{\prime}\right)\right]
$$


In a symmetric equilibrium, the decision rules satisfy $\hat{\pi}_{j}^{N}(B, s)=\hat{\pi}^{N}(B, s)$ and $\hat{h}_{j}(B, s)=$ $\hat{h}(B, s)$ for all firms. A recursive rational expectations equilibrium is defined below.

Definition 1 (Recursive Competitive Equilibrium). For a given government's policy rule $\pi_{t}^{N}(B, s)$, a recursive competitive equilibrium is defined by pricing functions $\left\{w(B, s), p^{N}(B, s)\right\}$, a perceived law of motion for aggregate bond holdings $\Gamma(B, s)$, firms' policies $\left\{\hat{\pi}^{N}(B, s), \hat{h}(B, s)\right\}$, and households' decision rules $\left\{\hat{b}^{\prime}(b, B, s), \hat{c}^{T}(b, B, s), \hat{c}^{N}(b, B, s), \hat{\ell}(b, B, s)\right\}$ with associated value function $V(b, B, s)$ such that:

1. $\left\{\hat{b}^{\prime}(b, B, s), \hat{c}^{T}(b, B, s), \hat{c}^{N}(b, B, s), \hat{\ell}(b, B, s)\right\}$ and $V(b, B, s)$ solve households' recursive optimization problem, taking as given $w(B, s), p^{N}(B, s)$ and $\Gamma(B, s)$.

2. $\left\{\hat{\pi}^{N}(B, s), \hat{h}(B, s)\right\}$ satisfies (12), taking as given $w(B, s), p^{N}(B, s)$ and $\pi^{N}(B, s)$.

3. The perceived law of motion for aggregate bonds and the government's policy rule are consistent with the actual law of motion for individual bonds and actual inflation policy, respectively: $\Gamma(B, s)=\hat{b}^{\prime}(B, B, s)$ and $\pi(B, s)=\hat{\pi}(B, s)$.

4. The labor market and the tradable good market clear

$$
\begin{aligned}
\hat{h}(B, s) & =\hat{\ell}(B, B, s) \\
\hat{c}^{T}(B, B, s)+\frac{\Gamma(B, s)}{R} & =y^{T}+B
\end{aligned}
$$

\section{$3 \quad$ Monetary Policy Analysis}

This section discusses the trade-off between macroeconomic stabilization and financial stabilization that a monetary policymaker faces in the model economy presented in the previous section and formally characterizes the optimal time-consistent monetary policy, that is the discretionary monetary policy.

I assume that the government (or central bank) lacks the ability to commit to future policies, and chooses its policy instruments subject to the credit constraint and all others competitive equilibrium conditions. Since the set of restrictions on the optimal policy includes forwardlooking constraints, namely the Euler equation for households (4) and an inter-temporal pricing rule for firms (10), the optimal policy setup amounts to a dynamic game between successive governments. Thus, following Klein et al. (2008) and Bianchi and Mendoza (2018), I focus on Markov-stationary policy rules that are expressed as functions of the payoff-relevant state variables $(B, s) .{ }^{4}$ To simplify the analysis of the discretionary policy in this section, I focus

\footnotetext{
${ }^{4} \mathrm{~A}$ Markov-perfect equilibrium is a fixed point in the policy rule chosen by the government in any given period, taking as given the policy rule that represent the future governments' decisions. The key property of this fixed point is that the policy rule of the current government matches the policy rules of future governments that the current government takes as given to solve its optimization problem.
} 
on additively separable preferences, that is preferences satisfying $u_{c, \ell}=0$. This specification of preferences is common in analytical studies of monetary policy open economy models (see for example Benigno and Benigno, 2003 and Gali and Monacelli, 2005). Appendix B.2 shows that the results are robust to alternatives specifications where preferences satisfies the form introduced by Greenwood et al. (1988), often referred to as GHH preferences. ${ }^{5}$

\subsection{Government's Optimization Problem}

Problem The government sets its policy to maximize the agents' welfare subject to the resource, credit and implementability constraints. Unlike private agents, the government internalizes the general equilibrium effects of borrowing decisions on market prices. To simplify the description of the government's optimal policy problem, I introduce the concept of a labor wedge, defined as the gap between firms' marginal product of labor in the non-tradable production sector and households' marginal rate of substitution between leisure and non-tradable consumption:

$$
\omega_{t} \equiv 1+\frac{1}{A} \frac{u_{\ell}(t)}{u_{N}(t)}
$$

The labor wedge is zero at efficient allocation. Let $\mathcal{M}(b, s)=\left(1+\hat{\pi}^{N}(b, s)\right) \hat{\pi}^{N}(b, s)$ be the monetary policy rule of future governments that the current government takes as given, and $\{\mathcal{C}(b, s), \mathcal{L}(b, s), \mathcal{B}(b, s), \mathcal{V}(b, s)\}$ the equilibrium functions that return the values of the corresponding variables under that policy rule. Taking these functions as given, the government's time-consistent problem in recursive form is:

$$
\begin{aligned}
& \mathcal{V}(b, s)=\max _{c^{T}, c^{N}, \ell, b^{\prime}, p^{N}, \pi^{N}, \mu} u\left[c\left(c^{T}, c^{N}\right), \ell\right]+\beta \mathbb{E}_{s^{\prime} \mid s} \mathcal{V}\left(b^{\prime}, s^{\prime}\right) \\
& \text { s.t. } \quad c^{N}=\alpha\left(p^{N}\right) c^{T} \\
& c^{N}=\left[1-\frac{\varphi}{2}\left(\pi^{N}\right)^{2}\right] A \ell \\
& c^{T}=y^{T}+b-\frac{b^{\prime}}{R} \\
& \frac{b^{\prime}}{R} \geq-\kappa\left(y^{T}+p^{N} c^{N}\right) \\
& \mu=u_{T}(c, \ell)-\beta R \mathbb{E}_{s^{\prime} \mid s} u_{T}\left(\mathcal{C}\left(b^{\prime}, s^{\prime}\right), \mathcal{L}\left(b^{\prime}, s^{\prime}\right)\right) \\
& \mu \quad \times\left[b^{\prime}+\kappa\left(y^{T}+p^{N} c^{N}\right)\right]=0, \mu \geq 0 \\
& 0=\varphi \pi^{N}\left(1+\pi^{N}\right)+(\varepsilon-1)\left[1-z^{-1}(1-\omega)\right]-\varphi \ell^{-1} \mathbb{E}_{s^{\prime} \mid s} \Lambda\left[\mathcal{L}\left(b^{\prime}, s^{\prime}\right) \mathcal{M}\left(b^{\prime}, s^{\prime}\right)\right]
\end{aligned}
$$

\footnotetext{
${ }^{5}$ This formulation of preferences is widely used in the growing macro-finance literature (see for example, Fornaro, 2015, Bianchi and Mendoza, 2018) for the purpose of the quantitative analysis. I provide further details on the properties of $\mathrm{GHH}$ preferences in section 4 and use this formulation for the quantitative analysis.
} 
where the variables $z_{t}$ and $\omega_{t}$ are respectively defined in (6) and (13). (15) is an intra-temporal implementability constraint, (16) is the resource constraint for the non-tradable good, (17) is the resource constraint for the tradable good, (18) is the credit constraint, (19)-(20) are the inter-temporal implementability constraints associated with households' borrowing choices, and (21) is the inter-temporal implementability constraint associated with firms' pricing decision (i.e., the non-linear New Keynesian Philipps Curve). I denote the multiplier on (17), (18), (19) by $\lambda^{*} \geq 0, \mu^{*} \geq 0$ and $v$. Note that $\lambda^{*}$ and $\mu^{*}$ differ from $\lambda$ and $\mu$.

Aggregate demand externality Factoring the non-tradable good's demand (15) and resource constraint (16) into the period utility function, an indirect utility function can be defined as $\mathcal{S}(t) \equiv u\left[c\left(c^{T}, \alpha\left(p^{N}\right) c^{T}\right),\left(1-\frac{\varphi}{2}\left(\pi^{N}\right)^{2}\right)^{-1} \alpha\left(p^{N}\right) c^{T}\right]$. The social marginal value of the tradable good consumption in equilibrium is given by:

$$
\frac{\partial \mathcal{S}(t)}{\partial c_{t}^{T}}=\left[1+\left(\frac{p_{t}^{N} y_{t}^{N}}{c_{t}^{T}}\right)\left(\omega_{t}-\frac{\varphi}{2}\left(\pi_{t}^{N}\right)^{2}\right)\right] u_{T}(t)
$$

There is thus a wedge between households' private marginal value of the tradable good and this social marginal value in equilibrium, due to the presence of an aggregate demand externality. This wedge is proportional to the labor wedge net of the cost of inflation, weighted by the relative expenditure share of the non-tradable good relative to the tradable good. ${ }^{6}$ To understand the source of this wedge, consider a marginal increase in households' tradable good consumption. Households only value this increase according to their private marginal utility $u_{T}(t)$. But as they increase their consumption of tradables, households also demand more non-tradables. And since price adjustment is costly, this larger demand translates into a partial price adjustment as well as into more non-tradable good production. These price and production adjustments have non-internalized welfare ramifications. The relevant non-tradable output multiplier is given by the relative expenditure share of the non-tradable to the tradable good $p_{t}^{N} y_{t}^{N} / c_{t}^{T}$, and the price and employment adjustment detailed above create a net benefit of $\omega_{t}-(\varphi / 2)\left(\pi_{t}^{N}\right)^{2}$. Therefore, the non-internalized benefit is precisely $\left(p_{t}^{N} y_{t}^{N} / c_{t}^{T}\right)\left(\omega_{t}-(\varphi / 2)\left(\pi_{t}^{N}\right)^{2}\right)$, which has a marginal utility $u_{T}(t)$.

Pecuniary externality The second externality present in this environment is a pecuniary externality originating from the credit constraint. To describe this externality, I compare the

\footnotetext{
${ }^{6}$ This result is in line with Farhi and Werning (2016). In a similar environment where firms sets their prices once and for all, they highlight the existence of an aggregate demand externality and show that the wedge between the social and private marginal values equals the weighted labor wedge; that is, the labor wedge weighted by the relative expenditure share of non-tradable goods relative to tradable goods.
} 
government's and households' bond choices in the absence of nominal rigidities (i.e. for $\varphi=0$ ). ${ }^{7}$ The government's optimal decision for bonds in sequential form can be described by the two equations: ${ }^{8}$

$$
\begin{aligned}
& \lambda_{t}^{*}=u_{T}(t)+\gamma^{-1} \kappa \frac{p_{t}^{N} c_{t}^{N}}{c_{t}^{T}} \mu_{t}^{*} \\
& \lambda_{t}^{*}=\beta R_{t} \mathbb{E}_{t} \lambda_{t+1}^{*}+\mu_{t}^{*}
\end{aligned}
$$

The pecuniary externality can be understood by comparing (24) with the corresponding households' optimality conditions (7). The government's shadow value of tradable consumption $\lambda_{t}^{*}$ is equal to the marginal utility of the tradable consumption, $u_{T}(t)$, plus an additional term that represents the relaxation effect on the credit constraint induced by the rise in the relative price of non-tradables associated with a marginally higher tradable consumption. The credit constraint relaxation term is absent from the private condition (7). As emphasized in the normative macro-finance literature (see Korinek, 2011 and Bianchi, 2011), this wedge between social and private valuations of tradable consumption, when the credit constraint is binding, generates overborrowing ex ante. Indeed, when the credit constraint is not currently binding, households equate the benefits $u_{T}(t)$ of an additional unit of borrowing to its private costs $\beta(1+r) \mathbb{E}_{t} u_{T}(t+1)$. However, the government has a higher marginal cost given by $\beta R_{t} \mathbb{E}_{t}\left[u_{T}(t+1)+\mu_{t+1}^{*} \Theta_{t+1}\right]$ with $\Theta_{t}=(1 / \gamma) \kappa p_{t}^{N} c_{t}^{N} / c_{t}^{T}$. The additional cost, $R_{t} \Theta_{t+1}$, incurred by the government represents how a one unit increase in borrowing at date $t$ tightens the ability to borrow at date $t+1$, which has a marginal utility cost of $\mu_{t+1}^{*}$.

\subsection{Discretionary Monetary Policy in Absence of Credit Frictions}

I start the normative analysis by considering a case in which the economy features unconstrained access to the international credit market. This economy can be regarded as a financially robust economy in which either there is no credit constraint, or the credit coefficient $\kappa$ is large enough that the credit constraint never binds. ${ }^{9}$ In this case, the only constraint faced by agents on their borrowing is their natural borrowing limit. The allocation of the competitive equilibrium in this economy is the same as the one described in Section 2 , but with $\mu_{t}=0$ for all $t$. This case will serve as a benchmark.

\footnotetext{
${ }^{7}$ When prices are flexible $(\varphi=0)$, there is no role for the monetary policy due to the dichotomy between nominal and real variables (see Lucas, 1972 and Caplin and Spulber, 1987).

${ }^{8}$ Because if the government decisions for bonds coincide with households decisions for bonds, the implementability constraint (19) would be always satisfied (that is, the associated multiplier would be equal to zero), the multiplier on this constraint is set to zero in order to discuss the presence of the externality.

${ }^{9}$ Absence of a credit constraint or higher values of $\kappa$ can be interpreted as representing a highly-developed financial system in which households are able to borrow against a large share of their total income.
} 
The discretionary monetary policy solves (B.2) subject to (15)-(17), (19) with equality $\mu_{t}=$ 0 and (21). The discretionary policy problem amounts to choosing a path for the inflation rate of the non-tradable good to maximize private agents' welfare. The following lemma describes the solution to this problem.

Proposition 1 (Discretionary Monetary Policy without Credit Frictions). With no credit frictions, a price stability policy (i.e. $\pi_{t}^{N}=0$ for all $t$ ) is the discretionary monetary policy. It perfectly stabilizes the economy (i.e. $\omega_{t}=0$ ), and the allocation satisfies (5), (11), $-u_{\ell}(t)=A u_{N}(t)$ along with $c_{t}^{N}=y_{t}^{N}=A \ell_{t}$.

Proof. See Appendix A.1

This result can be intuited from the observation that when there are no financial market imperfections (no credit frictions), the only distortions in this economy arise from price stickiness. Hence, as is standard in the New Keynesian literature, the optimal monetary policy eliminates the inefficiency stemming from sticky prices by making price adjustments unnecessary and production supply determined. Specifically, when the economy experiences a negative tradable endowment shock, private agents feel poor and want to reduce their demand for both goods. Firms in turn aim to adjust their price downward in response to the resulting decrease in the demand for non-tradables. The discretionary monetary policy thus features an exchange rate depreciation that generates expenditure switching toward the non-tradable good and renders an adjustment of the price of the non-tradable good unnecessary. Because the labor tax is assumed to be set to completely offset monopolistic distortions, the resulting allocation is efficient.

\subsection{Discretionary Monetary Policy in Presence of Credit Frictions}

I now turn to analyzing the discretionary monetary policy in an economy featuring limited access to the international credit market. The discretionary policy in this environment solves (B.2) subject to (15)-(21). The two aforementioned externalities create policy trade-offs in the presence of credit frictions, and a price stability policy is generally not optimal.

In what follows, a boom (a recession) in the non-tradable production sector corresponds to a situation in which the labor wedge is negative (positive), in line with the general class of New Keynesian models. ${ }^{10}$ The proposition below characterizes the discretionary monetary policy in the presence of credit frictions.

\footnotetext{
${ }^{10}$ In this class of models (see, among others, Gali and Monacelli, 2005 and Schmitt-Grohé and Uribe, 2007), there is a boom when the level of output is above its natural level, which is defined as the output level under flexible price allocation.
} 
Proposition 2 (Discretionary Monetary Policy). In the presence of credit frictions, the path of the inflation rate under the discretionary monetary policy satisfies:

$$
\begin{aligned}
\varphi\left(\Delta_{0, t}+\frac{\pi_{t}^{N}}{2}\right) y_{t}^{N} \pi_{t}^{N}= & y_{t}^{N} \omega_{t}+\varphi \mathbb{E}_{t}\left[\Delta_{1, t+1} \pi_{t+1}^{N}\right] \\
& +\left(\sigma-\gamma^{-1}\right) \frac{c_{T}(t)}{c_{t}} c_{t}^{N} v_{t}+\left(1-\gamma^{-1}\right) \kappa p_{t}^{N} c_{t}^{N} \frac{\mu_{t}^{*}}{u_{N}(t)}
\end{aligned}
$$

where $\Delta_{0, t}>0$. As a result, price stability is always optimal in the knife-edge case where $\gamma=\sigma=1$.

Proof. See Appendix A.2

Proposition 2 states that the inflation path under discretionary monetary policy is given by a targeting rule that is also a function of the labor wedge, the government's Lagrange multipliers on the credit constraint (18) and households' Euler equation (19). The first term accounts for the output stability motive of the government. It shows that the government engineers an expansionary monetary policy when there is a positive labor wedge, and a contractionary monetary policy when there is a negative labor wedge. The second term accounts for the price stability motive. It shows that if the government expects higher future inflation, it will already promote inflation in the current period to smooth out the necessary price adjustments. The last two terms account for monetary policy's response to the adverse effects stemming from the presence of credit constraints. How the monetary authority responds to financial conditions when the credit constraint is not binding $\left(v_{t} \neq 0\right)$ and when it is binding $\left(\mu_{t} \neq 0\right)$ is respectively embedded into the third and the fourth term, and depends on substitution elasticities.

When the constraint is not binding, the effectiveness of the monetary policy in correcting the pecuniary externality and preventing overborrowing depends on how an increase in the nontradable output and consumption affects households' private marginal utility of tradables (that is, their cost of borrowing), which is captured by the difference between the intra-temporal and the inter-temporal elasticity of substitution. Likewise, when the constraint binds, the effectiveness of the monetary policy in correcting the aggregate demand externality and tames the overheating induced by the excessive labor supply of private agents depends on how an increase in the non-tradable output and consumption affects the value of the collateral, which is captured by the intra-temporal elasticity of substitution.

The discretionary monetary policy thus strikes a compromise between price stability and financial stability. Notice that, this characterization of the discretionary monetary policy, given by equation (25), confirms the previous result that in absence of credit frictions (that is, for $\left.v_{t}=\mu_{t}=0\right)$ a price stability policy is optimal. The remarks below provide further details on the characterization of the discretionary policy with credit frictions. 
Remark 1 (Prudential Monetary Policy). When the credit constraint does not currently bind, a price stability policy is optimal if and only if $\gamma=1 / \sigma$. Further, for $\gamma>1 / \sigma$ the current government optimally deviates from price stability policy to perform an expansionary monetary policy.

This remark adds further insights and describes how monetary policy is used as a prudential tool. First, it is important to notice that the shadow of the implementability constraint (19), $v_{t}$, can be seen as a measure of the difference between socially desirable level of borrowing and private agents' level of borrowing. Because under a price stability policy private agents overborrow ex ante, $v_{t}>0,{ }^{11}$ the government does not use monetary policy solely to make any adjustments in the prices of non-tradables unnecessary, but also to address the pecuniary externality. In the knife-edge case where $\gamma=1 / \sigma$, the intra-temporal and the inter-temporal effects of the monetary policy stance on tradable consumption cancel each other out, thus generating either a boom or a bust in the non-tradable sector is impotent to address overborrowing. Therefore, in this case, the government only focuses on price stability and replicates flexible price allocation. When the intra-temporal elasticity of substitution is greater than the inter-temporal elasticity of substitution (i.e., when $\gamma>1 / \sigma$ ), an expansionary monetary policy generating a boom in the non-tradable sector reduces households' marginal propensity to consume the tradable good, contains the rise in the relative price of non-tradables and addresses overborrowing.

Remark 2 (Ex Post Policy). When the credit constraint binds, a price stability policy is optimal if and only if $\gamma=1$. Further, for $\gamma<1$ the current government optimally deviates from a price stability policy to perform a contractionary monetary policy.

When the credit constraint binds, the social marginal value of tradable consumption is $\mathcal{S}_{T}(t)=\left[1+\left(p_{t}^{N} c_{t}^{N} / c_{t}^{T}\right) \omega_{t}\right] u_{T}(t)<u_{T}(t)$, with $\omega_{t}=-\kappa \mu_{t} / u_{T}(t)<0$, and households overvalue the tradable good. The government then faces a trade-off between price stability and the relaxation of the credit constraint to address the aggregate demand externality. When the intra-temporal elasticity of substitution equals $1(\gamma=1)$, the effect on the relative price of nontradable cancels out the quantity effect when the economy is experiencing a boom or a bust in the non-tradable sector $\left(\partial p_{t}^{N} c_{t}^{N} / \partial c_{t}^{N}=0\right)$. Therefore, neither an expansionary policy nor a contractionary policy will have an effect on the value of the collateral. The government then has no incentive to deviate from a price stability policy. In contrast, when the intra-temporal elasticity of substitution is less than $1(\gamma<1)$, the price effect dominates the quantity effect $\left(\partial p_{t}^{N} c_{t}^{N} / \partial c_{t}^{N}<0\right)$. Thus, by performing a contractionary monetary policy and creating a recession, the current government sustains the value of the collateral, limits the fall in private agents' borrowing capacity and alleviates the effects of the aggregate demand externality.

${ }^{11}$ The analytical expression is $v_{t}=\sum_{j=1}^{\infty} \beta^{j} \mathbb{E}_{t}\left[\left(\Pi_{k=t}^{j} \frac{R_{t+k}}{\chi_{t+j}}\right) \Theta_{t+j} \mu_{t+j}^{*}\right]$, with $\chi_{t+j}=1+\frac{\beta R_{t+j} u_{T T}(t+j+1)}{u_{T T}(t+j)}>1$. 
Discussion Kaminsky et al. (2004) document that monetary policy is countercyclical in almost all the OECD countries while it is mostly procyclical in emerging market ones. ${ }^{12}$ This section highlights conditions under which procyclical monetary policy can be optimal in an economy in which financial markets are imperfect, capital flows freely and the government lacks commitment. Remarks 1 and 2 together show that the discretionary monetary policy is procyclical when the intra-temporal elasticity is greater than the inter-temporal elasticity and the former is less than $1(1 / \sigma<\gamma<1)$. The basic idea here is that, in an economy featuring an endogenous sudden stop mechanism, lowering the degree of nominal rigidity is not always welfare increasing due to the tradeoff between price and financial stability documented in this environment. When the economy is experiencing bad shocks that lead to capital outflows (that is periods in which the constraint binds), there are gains from moving away from a price stability policy to perform a contractionary monetary policy when goods are complements $(\gamma<1)$. In these circumstances, a contractionary monetary policy prevents large real exchange depreciation (fall of the relative price of non-tradables), slackens the credit constraint, restrain capital outflows and mitigates balance sheets effects. Furthermore, in advance of crisis periods (that is periods in which the credit constraint does not bind), good shocks lead to excessive capital inflows (overborrowing), and there are gains from moving away from a price stability policy to perform an expansionary monetary policy. This procyclical monetary policy increases the cost of borrowing, contains the current rise of the real exchange rate, and mitigate balance sheet effects from future depreciation.

\subsection{Discretionary Monetary Policy with Capital Flow Taxes}

I now consider the possibility of the government having an additional policy instrument consisting in capital flow taxes and look at how the availability of this additional tool affects the optimal design of monetary policy. The budget constraint of households is:

$$
c_{t}^{T}+p_{t}^{N} c_{t}^{N}+\frac{b_{t+1}}{R_{t}\left(1+\tau_{t}^{b}\right)}=y_{t}^{T}+w_{t} \ell_{t}+\phi_{t}+b_{t}+\mathcal{T}_{t}
$$

where $\mathcal{T}_{t}$ represents a lump-sum transfer that households receive from the government. The households' Euler equation for bonds becomes:

$$
u_{T}(t)=\beta R_{t}\left(1+\tau_{t}^{b}\right) \mathbb{E}_{t} u_{T}(t+1)+\mu_{t}
$$

\footnotetext{
${ }^{12}$ Kaminsky et al. (2004) use a sample of 21 OECD countries and 83 developing countries (which include 18 middle-high income countries). The procyclicality of the monetary policy is measured by the correlation between the cyclical components of the real GDP and the cyclical components of short-term interest rates (the interbank rate, the T-bill or the discount rate).
} 
Given quantities, the tax on debt can be used to back out households' Euler equation. It turns out that allowing the government to use capital taxes is equivalent to assuming that it controls the credit operations of households and rebates back the proceeds of the transactions in a lump-sum fashion. Hence, the government's optimal policy problem amounts to choosing the path for the inflation rate and making debt choices for households, while allowing them to choose their labor supply and their allocation of consumption between tradable goods and non-tradable goods in a competitive way. The government's optimization problem thus reduces to solving (B.2) subject to (15)-(18) and (21). ${ }^{13}$ The following proposition characterizes the discretionary monetary policy in an economy with credit frictions when capital flow taxes are used optimally.

Proposition 3 (Discretionary Policy under Availability of Capital Flow Taxes). When capital flow taxes are available, the path of the inflation rate under the discretionary monetary policy satisfies:

$$
\varphi\left(\Delta_{0, t}+\frac{\pi_{t}^{N}}{2}\right) y_{t}^{N} \pi_{t}^{N}=y_{t}^{N} \omega_{t}+\varphi \mathbb{E}_{t}\left[\Delta_{1, t+1} \pi_{t+1}^{N}\right]+\left(1-\gamma^{-1}\right) \frac{\kappa}{u_{T}(t)} \mu_{t}^{*}
$$

As a result, price stability is always optimal when $\gamma=1$.

Proof. See Appendix A.3

This proposition provides insight into how the availability of capital flow taxes changes the discretionary monetary policy. When the credit constraint binds, the design of the discretionary monetary policy is quite similar to that in an economy where capital flow taxes cannot be used. In that case, the discretionary monetary policy is a compromise between two objectives: correcting nominal rigidities (macroeconomic stability) and relaxing the credit constraint to correct aggregate demand externalities (financial stability). The government optimally stabilizes prices if the intra-temporal elasticity of substitution equals $1(\gamma=1)$, and deviates from a price stability policy to create a recession if $\gamma<1$. However, when the credit constraint does not currently bind, the discretionary monetary policy is qualitatively different from the case where capital flow taxes are not available. In this case, capital flow taxes appear to be the preferred tool for correcting the pecuniary externality, and the monetary policy focuses on granting price stability.

The proposition also shows that the conditions under which a price stability policy is optimal in the absence of capital flow taxes are a subset of those when capital flow taxes are available and used optimally. In the latter, the discretionary monetary policy is a price stability policy

\footnotetext{
${ }^{13}$ Appendix A.3 shows that any allocation that satisfies (15)-(18) and (21) also satisfies the general equilibrium.
} 
when $\gamma=1$, while in the former a price stability policy is optimal only under the more restrictive aforementioned conditions $(1 / \sigma=\gamma=1)$.

\section{Quantitative Analysis}

This section evaluates the quantitative implications of the model. I solve numerically for the problem of the government, under both free capital mobility and availability of capital flow taxes, using global non-linear methods. I also solve for the competitive equilibrium in which the monetary policy is characterized by a price stability policy.

\subsection{Calibration}

The model is calibrated to annual data from Argentina. Preferences in this section are specified following Greenwood et al. (1988) where utility is defined in terms of the excess of consumption over the disutility of labor $u\left(c_{t}-g\left(\ell_{t}\right)\right)$, and $g\left(\ell_{t}\right)$ is a function that measures the disutility of the labor supply. This formulation of preferences allows international real business cycle models to explain observed business cycle facts, and delivers realistic/empirically plausible, dynamics for employment in emerging economies. The functional forms for preferences are:

$$
\begin{aligned}
u(c-g(\ell)) & =\frac{(c-g(\ell))^{1-\sigma}}{1-\sigma}, \text { and } \\
g(\ell) & =\chi \frac{\ell^{1+\theta}}{1+\theta}
\end{aligned}
$$

The coefficient of relative risk aversion is set to $\sigma=2$, a standard value in the real business cycle literature for small open economies. In line with evidence by Kimball and Shapiro (2008), the Frisch elasticity of labor supply $1 / \theta$ is set to 1 . The labor disutility parameter $\chi$ is set so that mean employment in the non-tradable sector is equal to 1 , which requires $\chi=0.69$. The elasticity of substitution among differentiated intermediate goods $\varepsilon$ is set to 7.66, corresponding to a $15 \%$ net markup that is in the range found by Diewert and Fox (2008). I also set the Rotemberg price adjustment cost parameter to ensure that nominal prices are sticky for three quarters on average, which requires $\varphi=62 .{ }^{14}$ The value of the total factor productivity (TFP) in the non-tradable sector is normalized to 1 . The process for the exogenous driving forces

\footnotetext{
${ }^{14}$ The parameter $\varphi$ is set to ensure that the first-order approximation of the New-Keynesian Phillips curve (NKPC) in the current Rotemberg model, equation (10), is equivalent to the one in a Calvo model where firms keep their price unchanged with a probability $\delta$. The log-linear version of the NKPC is: $\hat{\pi}_{t}^{N}=\beta \hat{\pi}_{t+1}^{N}+\bar{\kappa} \hat{y}_{t}^{N}$, where $\hat{y}_{t}^{N}$ represents the output gap, $\bar{\kappa}=(\varepsilon-1) / \varphi$ in this model and $\bar{\kappa}=(1-\delta)(1-\beta \delta) / \delta$ in the Calvo model.
} 
Table 1: Calibration

\begin{tabular}{lll}
\hline \hline Description & Parameter-Value & Source/Target \\
\hline Risk aversion & $\sigma=2$ & Standard value \\
Frisch elasticity parameter & $\theta=1$ & Kimball and Shapiro $(2008)$ \\
Elasticity of substitution & $\gamma=0.83$ & Conservative value \\
Monopoly power & $\varepsilon=7.66$ & $15 \%$ net markup \\
Adjustment cost parameter & $\varphi=62$ & Three quarter of price stickiness \\
Discount factor & $\beta=0.905$ & Average NFA-GDP ratio $=-29 \%$ \\
Weight on tradables in CES & $a=0.315$ & Share of tradable output $=32 \%$ \\
Collateral coefficient & $\kappa=0.319$ & Frequency of crisis $=5.5 \%$ \\
Labor disutility coefficient & $\chi=0.686$ & Mean labor $=1$ \\
TFP in non-tradable sector & $A=1$ & Normalization \\
\hline
\end{tabular}

$s_{t}=\left(y_{t}^{T}, R_{t}\right)$ is taken to be a first-order bivariate autoregressive process

$$
\left[\begin{array}{l}
\ln \left(y_{t}^{T}\right) \\
\ln \left(\frac{R_{t}}{\bar{R}}\right)
\end{array}\right]=\rho_{s}\left[\begin{array}{c}
\ln \left(y_{t-1}^{T}\right) \\
\ln \left(\frac{R_{t-1}}{\bar{R}}\right)
\end{array}\right]+\left[\begin{array}{c}
\epsilon_{t}^{T} \\
\epsilon_{t}^{R}
\end{array}\right] \quad \text { where } \quad\left[\epsilon_{t}^{T}, \epsilon_{t}^{R}\right] \sim \text { i.i.d. } N\left(0, \Sigma_{\epsilon}^{2}\right)
$$

I estimate this process by OLS with the risk-free rate and the cyclical component of tradable GDP from the World Development Indicators for the 1965-2014 period. The risk-free rate is measured by a U.S. real interest rate (Treasury-bill rate, deflated with expected U.S. CPI inflation). The tradable endowment is measured with the cyclical component of value added in agriculture and manufacturing. The OLS estimates of $\rho_{s}$ and $\Sigma_{\epsilon}$ are respectively

$$
\hat{\rho}_{s}=\left[\begin{array}{rr}
0.6663 & -0.5238 \\
0.0842 & 0.7861
\end{array}\right], \quad \hat{\Sigma}_{\epsilon}=\left[\begin{array}{rr}
0.0028889 & -0.0001182 \\
-0.0001182 & 0.0001648
\end{array}\right] \text { and } \bar{R}=1.0219
$$

The vector of shocks is discretized into a first-order Markov process, with seventeen points, using the quadrature-based procedure of Tauchen and Hussey (1991). The mean of the endowment is set to 1 without loss of generality.

The parameters $\{\gamma, \beta, a, \kappa\}$ are calibrated following the baseline calibration of Bianchi (2011). The calibration strategy consists in choosing values for the parameters so that the model economy under the procyclical discretionary monetary policy matches some key aspects of the Argentina data. The intra-temporal elasticity of substitution between tradable and nontradable goods, $\gamma$, is set to a conservative value of 0.83 . The three parameters $\{\beta, a, \kappa\}$ are respectively set so that the long-run moments of the equilibrium under the procyclical monetary policy match the following three historical moments of the data: $(i)$ an average net foreign asset position to GDP of -29 percent, $(i i)$ a share of tradable goods in production of 32 percent 
and (iii) an observed frequency of 5.5 percent of "Sudden Stops". Sudden Stops are defined as events in which the credit constraint binds, and this leads to an increase in net capital outflows that exceeds one standard deviation. This approach leads to $\beta=0.905, a=0.315$ and $\kappa=0.319$.

\subsection{Policy Functions}

I start by analyzing the policy functions under different monetary regimes. I consider an inflation targeting regime in which the policy rule is set to stabilize the producer price index by offsetting all of the distortions originating from nominal rigidities, and there is no tax on capital. This regime captures the price stability objective of central banks. I also consider discretionary monetary policy regimes with and without capital flow taxes, under which the monetary policy is characterized by the discretionary monetary policy rules derived in section 3.3.

Figure 1 plots the decision rules as a function of the current holdings of bonds for a negative one-standard deviation shock. The presence of the endogenous borrowing constraint generates a kink in the policy function, and the bond decision rule is non-monotonic. I distinguish two different regions in each panel below focusing on the change in the slope of the borrowing decision rule under an inflation targeting regime, which occurs at the point where the credit constraint binds. The solid red line corresponds to the bond decision rule under an inflation targeting regime. The dashed blue line and the dashed-dotted black line corresponds to the bond decision rule under a discretionary monetary policy regime, with and without capital flow taxes, respectively.

The constrained region (shaded region) represents the situations in which the current debt level is sufficiently high such that the credit constraint binds under an inflation targeting regime. In this region, under an inflation targeting regime, by the market clearing condition for the tradable good (11) for a given choice of next-period level of debt, an increase in the current level of debt would imply a decrease in tradable consumption. Notice that because the intratemporal elasticity of substitution is less than $1(\gamma<1)$, the price effect dominates the quantity effect. Thus, the decrease of the relative price of non-tradables dominates the increase in the demand of non-tradables that accompanies the decrease in tradable consumption, which means that the next-period level of debt must be decreased further to satisfy the credit constraint.

Under both discretionary monetary policy regimes, the government uses its policy instrument (here, the exchange rate) to increase the relative price of non-tradables and sustain the value of the collateral, which means that households can borrow more. Moreover, the increase in the relative price of non-tradables implies a lower marginal cost. Thus, for a given future 

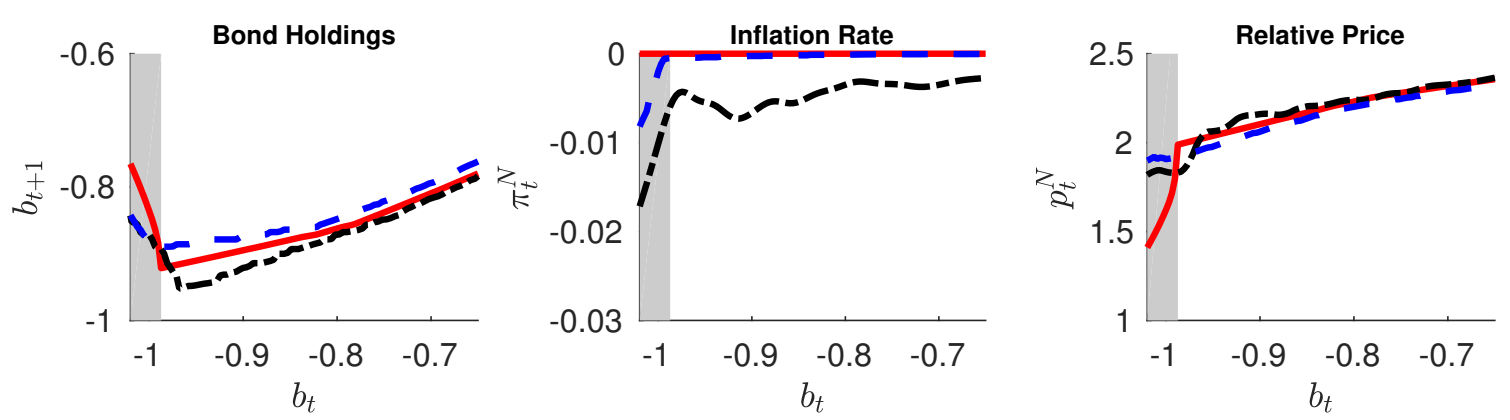

Inflation Targeting Policy - = Discretionary Monetary Policy without CFT

Figure 1: Decision rules for negative one-standard-deviation shocks

government policy, monopolistically competitive firms reduce prices of the non-tradable good by equation (10), which in turn generates a lower level of inflation when compared to its level under the inflation targeting regime.

In the unconstrained region, which corresponds to the state-space where the credit constraint does not bind, under a monetary regime that replicates flexible price allocation (an inflation targeting regime), households do not accumulate sufficient precautionary savings, due to the presence of the pecuniary externality. Under discretionary monetary policy regimes, the government also uses its policy instruments to increase the cost of borrowing and prevent a larger drop in households' borrowing ability if the credit constraint becomes binding in the next period. Without capital flow taxes (CFT), given future policies lowering the exchange rate level to increase the relative price of non-tradables has two effects: an inter-temporal effect that reduces the cost of borrowing since it is relatively cheaper to purchase debt, and an intra-temporal effect that increases the cost of borrowing since the non-tradable good is relatively more expensive. As shown in Proposition 2, since the intra-temporal effect dominates $(\gamma>1 / \sigma)$, the optimal policy is expansionary and thus generates a higher level of debt. Furthermore, a higher relative price of non-tradables implies that firms face lower marginal costs and then adjust their nominal prices downward according to their optimal pricing decision given by equation (10). The inflation rate under an optimal discretionary monetary policy regime without capital flow taxes thus turns out to be lower than under an inflation targeting regime. Under the discretionary monetary policy regime with capital flow taxes, the government uses taxes to control for households' credit operations and the monetary policy focuses only on stabilizing prices, as implied by Proposition 3. Thus, households accumulate uniformly lower levels of debt, which in turn help contain the rise in the relative price of non-tradables under a flexible price allocation and prevent a larger drop in households' borrowing ability if the credit constraint becomes binding in the next period. 


\subsection{Monetary Regimes and the Dynamics of Financial Crises}

This section analyzes the costs and gains associated with the adoption of an inflation targeting regime as opposed to a discretionary monetary policy regime, in an economy in which capital flows are free (i.e. in the absence of capital controls).

\subsubsection{Economic Behavior During Crises}

To describe the effectiveness of a discretionary monetary policy regime in reducing the severity of crises, I construct an event analysis using simulated data and analyze the dynamics of the economy during financial crises. A financial crisis is defined as a period in which the credit constraint is binding, and in which the current account is one standard deviation above its mean in the ergodic distribution corresponding to the economy under each monetary regime.

The construction of the event analysis follows the procedure proposed by Bianchi and Mendoza (2018). First, the model economy under an inflation targeting regime is simulated for 500,000 periods. After dropping the first 1,000 periods and identifying all of the crisis events under an inflation targeting regime, I construct five-year event windows centered in the period in which the crisis takes place. Then at each period, I compute averages for each simulated variable across the event windows in each year $t-2$ to $t+2$, and produce the economic dynamic under an inflation targeting regime. An initial value for bonds and a five-year sequence of tradable realizations is determined by calculating the median initial debt at $t-3$, and the median tradable shock across a cross-section of crisis events. Finally, I feed this sequence of shocks and initial value of bonds into the decision rules of the model economy under discretionary monetary policy regimes and compute the corresponding endogenous variables. ${ }^{15}$ The model's predictions during financial crises for both monetary regimes is depicted by Figure 2.

The top middle panel shows that, under the discretionary monetary policy regime without capital flow taxes, there is a negative inflation rate in the run-up to crises. The reduction of the inflation level (-3.0 percent) is more important in the year of the crisis. In this way, the government allows for more credit access, and the economy under this monetary regime features more debt than the economy under an inflation targeting regime during crises but also in the years before and after the occurrence of the crises (see the bottom right panel). As a result, consumption of the tradable good falls by a much smaller percentage during crises than it does the under the inflation targeting regime (-28.1 vs. -33.3 percent). This relatively large fall of tradable consumption under the inflation targeting regime arises because the binding credit constraint forces households to reduce their next period level of debt, as captured by the sharp

\footnotetext{
${ }^{15}$ This procedure ensures that the dynamics under each model economy are simulated using the same initial state and the same sequence of shocks.
} 

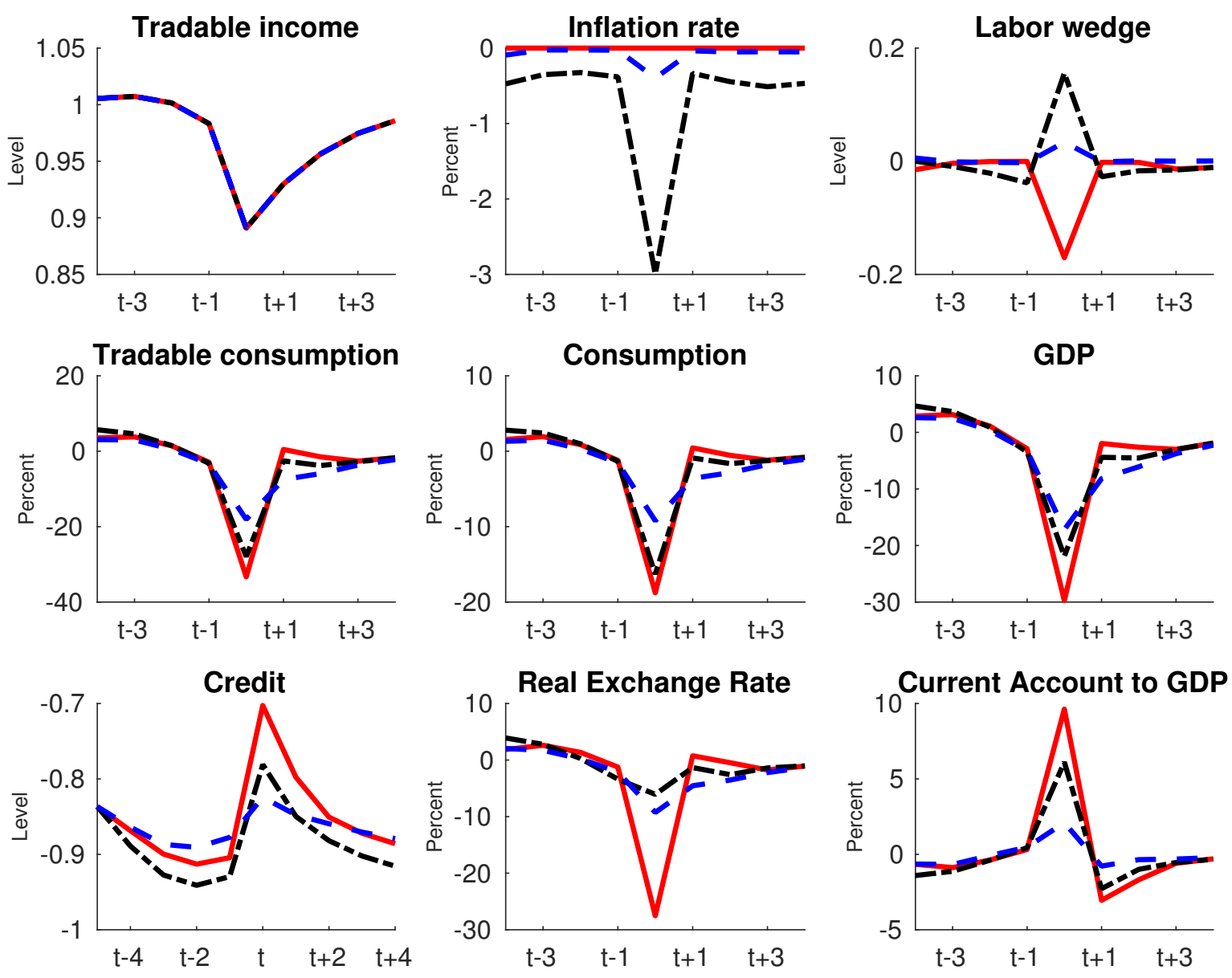

Inflation Targeting Policy - - - Discretionary Monetary Policy without CFT - - Discretionary Monetary Policy with CFT

Figure 2: Comparison of crises dynamics

Note: The real exchange rate, tradable consumption, consumption and GDP are expressed in percentage deviations from averages in the ergodic distribution. 
reversal of the current account-to-GDP ratio. Under the discretionary monetary policy regime, the government generates a boom ahead of financial crises and a recession during crises, as measured by the negative labor wedge, to sustain the value of the collateral. As a consequence, the fall in the real exchange rate is smaller during crises (-6.0 vs. -27.5 percent under the inflation targeting regime), which in turn mitigates the drop-in output and absorption during crises. The middle panel of Figure 2 shows that, in contrast to a discretionary monetary policy regime, decline in the total output and consumption is larger under inflation targeting: total output and consumption drop by 21.9 and 18.0 percent, respectively, under the discretionary monetary policy regime (vs. 29.7 percent for total output and 18.8 percent for consumption under the inflation targeting regime).

\subsubsection{Economic Behavior ahead of Potential Crises}

I now turn to analyzing the impact of monetary policy on debt accumulation and the frequency of crises in sudden stop-prone economies. In the absence of capital flow taxes, because households in an economy under an inflation targeting regime fail to accumulate sufficient precautionary savings due to the pecuniary externality, the government optimally deviates from a price stability policy to sustain the value of the collateral ahead of a potential financial crisis. Therefore, as shown in figure 3, the economy under the discretionary monetary policy regime is likely to have higher debt than the economy under an inflation targeting regime.

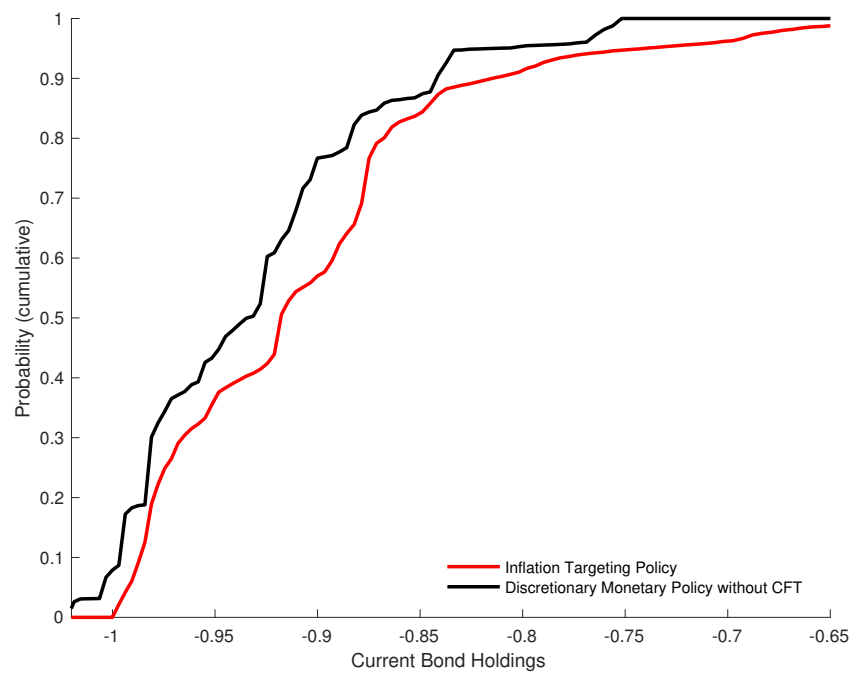

Figure 3: Distribution of bond holdings.

Formally, there is a 7.6 percent chance that households in the economy under the discretionary monetary policy regime carry an amount of debt larger than -1.0, which corresponds to the maximum amount of debt that households in the economy under an inflation targeting regime 
can hold. It is then apparent that the long-run probability of financial crises is 5.5 percent under the discretionary monetary policy regime versus 4.3 percent under an inflation targeting regime.

\subsubsection{Monetary Policy and Capital Controls}

The use of capital controls in the form of capital flow taxes along with a time-consistent monetary policy appears to be very effective in reducing the magnitude of crises as shown in Figure 2. Ahead of potential financial crises, taxes are used to diminish households' debt and restrain the boom in tradable consumption. This in turn prevents a larger drop in households' borrowing ability during crises, as captured by the smaller reversal of the current account-to-GDP ratio. The decline in tradable consumption, aggregate consumption and total output are thus smaller than their decline under both the discretionary monetary policy regime without capital flow taxes and the inflation targeting regime. Moreover, since the government uses taxes on debt to encourage households to accumulate sufficient precautionary savings, the economy under the discretionary monetary policy regime is less vulnerable to financial crises.

Table 2: Probability and severity of crises

\begin{tabular}{lccccc}
\hline \hline & \multicolumn{2}{c}{ Inflation Targeting } & & \multicolumn{2}{c}{ Time-Consistent } \\
\cline { 2 - 3 } \cline { 5 - 6 } & no CFT & with CFT & & no CFT & with CFT \\
\hline Probability of crises & 4.3 & 1.3 & & 5.5 & 1.1 \\
\hline Current-Account to GDP & 9.6 & 2.4 & & 6.2 & 2.1 \\
Real exchange rate depreciation & 27.5 & 11.4 & & 6.1 & 8.3 \\
Output & & & & & \\
$\quad$ average & -29.7 & -17.8 & & -21.9 & -17.2 \\
$\mathbb{P}(\hat{y}<-20 \%)$ & 87.7 & 24.4 & & 80.3 & 14.8 \\
Consumption & & & & & \\
$\quad$ average & -18.8 & -9.6 & & -18.0 & -9.2 \\
$\mathbb{P}(\hat{c}<-15 \%)$ & 83.3 & 8.1 & & 78.9 & 7.2 \\
\hline \hline
\end{tabular}

Note: Consumption, output and real exchange rate are expressed in percentage deviations from averages in the corresponding ergodic distribution.

Table 2 highlights the importance of capital flow taxes in reducing the long-run frequency of crises regardless of the monetary regime. The long-run probability of crises is 1.1 percent under a discretionary monetary policy regime with capital flow taxes, and 1.3 percent under an inflation targeting regime with capital flow taxes (vs. 4.3 percent an under inflation targeting regime, and 5.5 percent under a discretionary monetary policy regime). Table 2 also points out the role of capital flow taxes in reducing the severity of crises. Because monetary policy is less effective in correcting the pecuniary externality, the drop in capital inflows is more 
pronounced when capital flows taxes are not available. The probability that the decline in total output will exceed 20 percent is 80.3 percent under a discretionary monetary policy regime, and 14.8 percent under a discretionary monetary policy regime with capital flow taxes (87.7 percent under inflation targeting vs. 24.4 percent under inflation targeting with capital flow taxes). Further, the probability that the consumption will drop by more than 15 percent is 78.9 percent under a discretionary monetary policy regime, and 7.2 percent under a discretionary monetary policy regime with capital flow taxes (83.3 percent under inflation targeting vs. 8.1 percent under inflation targeting with capital flow taxes). These results from Table 2 suggests that monetary policy should be supplemented with capital flows taxes.

Another important result is that the design of the monetary policy also affects the optimal tax rate on debt. It is apparent that the optimal tax rate under the discretionary monetary policy regime is higher than under the inflation targeting regime. On average, tax on debt is about 6.1 percent under a discretionary monetary policy regime and 5.0 percent under an inflation targeting regime. This finding can be inferred from the fact that under a discretionary monetary policy regime, the government uses its monetary policy to allow for more credit access during crises. Further, because future choices of bond holdings affect current optimal choices, the government needs to raise (relatively) more taxes in order to cause households to accumulate a socially desirable level of debt. This additional result suggests that monetary policy and macroprudential policy are complementary.

\subsection{Long-run moments}

The table below depicts unconditional second moments computed using the ergodic distribution for the economy under each monetary regime considered. In line with the macro-finance literature, this model, which incorporates an occasionally binding credit constraints, accounts for some key regularities of the business cycles of emerging countries: the variability in GDP is higher than the variability in consumption and the strong procyclicality of capital flows. Furthermore, Table 3 points toward strong effects of monetary regimes on the volatility of the macroeconomic indicators, especially GDP, consumption, unemployment, and real exchange rate.

The first result from Table 3 enhances the existence of a trade-off between the variability in GDP and employment. Indeed, compared to the economy under a discretionary monetary policy regime, the economy under an inflation targeting regime features lower business cycle variability in employment and consumption, pointing to the importance of price stability policy in absorbing shocks and stabilizing employment. By stimulating employment and reducing the variability in the relative price of non-tradables during episodes of financial crises, a dis- 
Table 3: Second Moments

\begin{tabular}{lccccccc}
\hline \hline & \multicolumn{2}{c}{ Inflation Targeting } & & \multicolumn{2}{c}{ Time-Consistent } & Data \\
\cline { 2 - 3 } & no CFT & with CFT & & no CFT & with CFT & \\
\hline Standard Deviations & 5.4 & 5.2 & & 7.3 & 5.7 & 6.2 \\
Consumption & 2.3 & 2.8 & & 5.3 & 3.4 & 2.9 \\
Employment & 8.5 & 6.7 & & 6.5 & 5.9 & 8.2 \\
Real Exchange Rate & 2.9 & 1.3 & & 2.0 & 1.2 & 3.0 \\
Current Account-GDP & 3.1 & 1.4 & & 2.1 & 1.2 & 2.8 \\
Trade Balance-GDP & & & & & & \\
& & & & & & & \\
Correlation with GDP & 0.93 & 0.98 & & 0.88 & 0.96 & 0.88 \\
Consumption & 0.80 & 0.99 & & 0.69 & 0.95 & 0.74 \\
Employment & -0.65 & -0.54 & & -0.59 & -0.54 & -0.63 \\
Current Account-GDP & -0.65 &
\end{tabular}

Notes: Data are annual from WDI and Global Financial Data (GFD). Data period covers 1965-2014.

cretionary monetary policy regime lowers the volatility of the real exchange rate, the current account-to-GDP ratio, and the trade balance-to-GDP ratio. Table 3 further highlights the strong role of capital flow taxes in stabilizing the economy regardless the monetary regime considered. As discussed by Bianchi (2011) and Fornaro (2015), there are two main reasons for this to happen: the probability of crises is much larger in an economy where capital flow taxes are not available, and the externalities interfere with households' desire to smooth consumption over time. Clearly, when there is a bad shock and the credit constraint binds, households are forced to reduce their debt, which in turn generates a countercyclical current account balanceto-GDP ratio. Thus, the correlation of the current account-to-GDP ratio with the GDP is key to explaining the role played by capital flow taxes in smoothing consumption. From table 3, the lowest countercyclicality of the current account-to-GDP ratio is obtained when capital flow taxes are used optimally. The consumption smoothing therefore works better under a monetary regime with capital flow taxes.

\subsection{Welfare Effects}

The welfare implications of a monetary regime for each initial state, denoted $\lambda(b, s)$, is defined as the percent variation in the lifetime consumption stream that equalizes the expected utility of an household living in the economy under the discretionary monetary policy regime without capital flow taxes (TC) to the expected utility of an household living in an economy under the alternative monetary regime (AP) considered. Formally, for each initial state $(b, s)$, the welfare 
implications of the alternative monetary regime are computed as follows:

$$
\mathbb{E}_{0} \sum_{t=0}^{\infty} \beta^{t} u\left(c_{t}^{T C}(1+\lambda)-g\left(\ell_{t}^{T C}\right)\right)=\mathbb{E}_{0} \sum_{t=0}^{\infty} \beta^{t} u\left(c_{t}^{A P}-g\left(\ell_{t}^{A P}\right)\right)
$$

where $c_{t}^{s}$ and $\ell_{t}^{s}$ denote consumption and labor supply allocations under the monetary regime $s \in\{T C, A P\}$. Figure 4 depicts the welfare gains of moving away from the discretionary monetary policy regime without capital flow taxes to an alternative monetary regime as a function of the current level of bond holdings, and for negative, one standard deviation shocks.

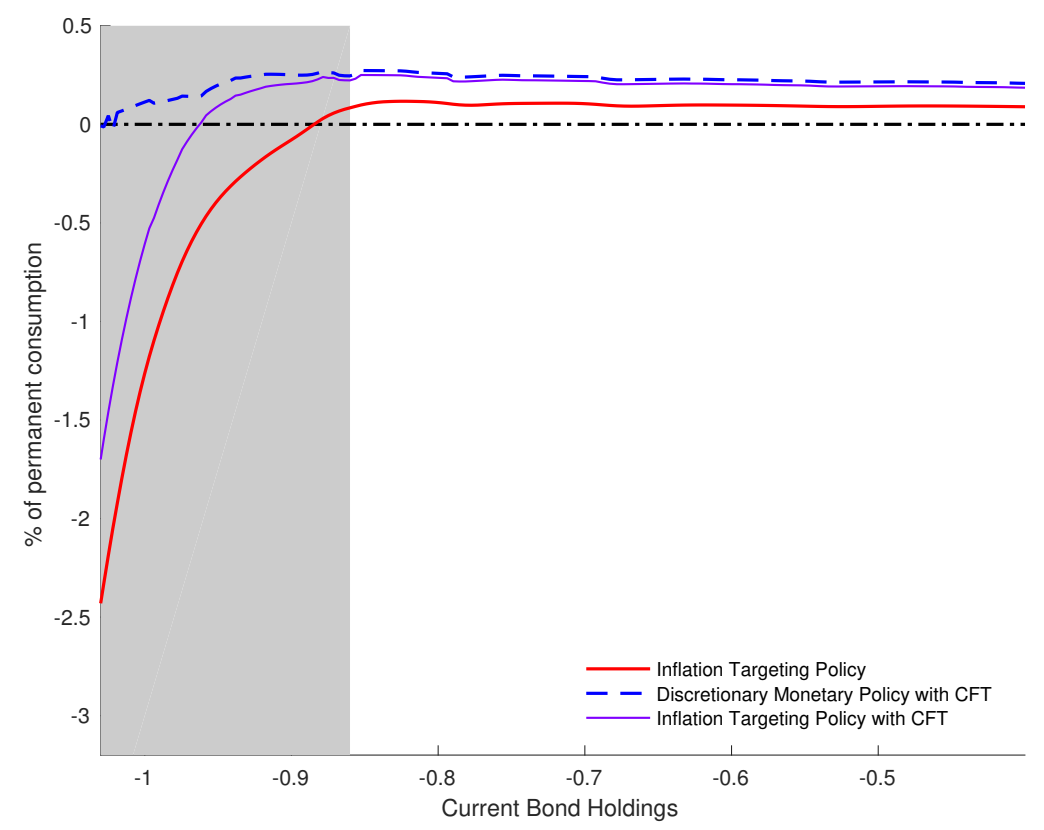

Figure 4: Welfare gains/costs of moving away from the procyclical discretionary monetary policy regime.

First, in the unconstrained region, the monetary regimes with capital flows taxes deliver larger welfare gains. This is because with capital flow taxes used by the government to address the pecuniary externality, households living in an economy under one of the monetary regimes with capital flow taxes act in a more precautionary way and the welfare increases. Furthermore, Figure 4 shows that, when capital flow taxes cannot be used, there are welfare gains from adopting an inflation targeting regime rather than the discretionary monetary policy regime. The rationale is that under the discretionary monetary policy regime, the government selects the best action given the current situation, which does not result in the social objective function being maximized. Rather, by relying on the inflation targeting policy rules, economic performance is improved (Kydland and Prescott, 1977).

Secondly, in the region where the credit constraint binds, comparing the welfare effects under both the inflation targeting regime and the effect under the discretionary monetary policy 
regime with capital flow taxes, it is apparent that monetary policy is more effective in correcting demand externalities than capital flow taxes. In this region, under the time-consistent monetary policy, the government sustains the value of the collateral, allows for more credit access and significantly improve social welfare. It is also important to notice that there are benefits from using capital controls under the inflation targeting regime, in contrast to the previous studies (e.g. Bianchi, 2011 and Ottonello, 2015) where the welfare gain from using capital flow taxes under a policy that replicates the flexible price allocation arises only in relation to how future allocations will differ. The reason is that, in this environment, when the credit constraint binds, capital flow taxes are used to offset the intra-temporal distortion in the labor supply decision and stabilize the economy.

I also calculate the average welfare gain $\bar{\lambda}$ as the average $\lambda(b, s)$ computed with the ergodic distribution in the economy under the discretionary monetary policy regime without capital flow taxes. Because when capital flow taxes cannot be used, an inflation targeting policy only delivers welfare losses in the constrained region, and the economy under this monetary regime spends less than 16 percent of the time in this region, on average there are welfare gains of adopting an inflation targeting regime rather than the discretionary monetary policy regime, which corresponds to 0.04 percent of permanent consumption. Another key result of this welfare analysis indicates the importance of capital flows taxes in changing the desirable property of the discretionary monetary policy regime. The discretionary monetary policy regime with capital flow taxes delivers the largest welfare gain (0.16 percent of permanent consumption). In comparison, the welfare gain from using capital flow taxes under the inflation targeting regime is only 0.14 percent of permanent consumption.

\section{Conclusion}

This paper provides an explanation to why monetary policy is procyclical in emerging economies using a small open economy model in which domestic agents face a credit constraint that limits borrowing to a fraction of their current income. The procyclicality of monetary policy is the result of the lack of commitment and the risk of capital account reversals (i.e. Sudden Stops). The discretionary monetary policy is contractionary during Sudden Stops to appreciate the real exchange rate, sustain the value of the collateral and relax binding financial constraints faced by domestic agents. During tranquil times, the discretionary monetary policy is procyclical because the expectation of monetary policy interventions ex post exacerbates the overborrowing problem. This policy then reduces domestic agents' marginal propensity to consume the tradable good, so as to mitigate overborrowing by private agents. Quantitatively, committing 
to an inflation targeting regime dominates the discretionary monetary policy regime in term of welfare. In addition, relative to the discretionary monetary regime, it reduces the occurence of financial crises although there are more severe when they occur. The quantitative analysis also suggests that there is much to be gained when monetary policy and macroprudential regulation such as capital controls are conducted jointly. Prudential capital controls are found to be very effective in correcting the externality stemming from financial constraints and make the discretionary monetary policy less procyclical, which as a result reduce excessive risk exposure of the economy, and deliver higher social welfare. 


\section{References}

Acharya, Sushant and Julien Bengui, "Liquidity Traps, Capital Flows," Journal of International Economics, 2018, 114, 276-298.

Aghion, Philippe, Philippe Bacchetta, and Abhijit Banerjee, "A corporate balancesheet approach to currency crises," Journal of Economic Theory, 2004, 119 (1), 6-30.

Bengui, Julien and Javier Bianchi, "Capital Flow Management when Capital Controls Leak," 2014. Mimeo, University of Montreal.

Benigno, Gianluca and Pierpaolo Benigno, "Price Stability in Open Economies," Review of Economic Studies, 2003, 70 (4), 743-764.

_, Huigang Chen, Christopher Otrok, Alessandro Rebucci, and Eric Young, "Monetary and Macro-Prudential Policies: An Integrated Analysis," 2011. Mimeo, London School of Economics.

${ }_{-},,_{-},,_{-}$, and $\ldots$, "Financial crises and macroprudential policies," Journal of International Economics, 2013, 89 (2), 453-470.

Bianchi, Javier, "Overborrowing and systemic externalities in the business cycle," American Economic Review, 2011, 101 (7), 3400-3426.

- and Enrique Mendoza, "Optimal Time-Consistent Macroprudential Policy," Journal of Political Economy, 2018, 126 (2), 588-634.

Braggion, Fabio, Lawrence Christiano, and Jorge Roldos, "Optimal monetary policy in a 'sudden stop'," Journal of Monetary Economics, 2009, 56, 582-595.

Caballero, Ricardo and Avrind Krishnamurthy, "Inflation targeting and sudden stops," 2003. NBER Working Paper No. 9599.

Calvo, Guillermo, "Capital flows and capital-markets crises: The simple economics of sudden stops," Journal of Applied Economics, 1998, 1 (1), 35-54.

Caplin, Andrew and Daniel Spulber, "Menu Costs and the Neutrality of Money," The Quarterly Journal of Economics, 1987, 102 (4), 703-726.

Céspedes, L. Felipe, Roberto Chang, and Andrés Velasco, "Balance Sheets and Exchange Rate Policy," American Economic Review, 2004, 94 (4), 1183-1193. 
Christiano, Lawrence, Christopher Gust, and Jorge Roldos, "Monetary policy in a financial crisis," Journal of Economics Theory, 2004, 119 (1), 64-103.

Clarida, Richard, Jordi Gali, and Mark Gertler, "A Simple Framework for International Monetary Policy Analysis," Journal of Monetary Economics, 2002, 49 (5), 879-904.

Curdia, Vasco, "Monetary Policy under Sudden Stops," 2007. Federal Reserve Bank of New York. Staff Reports.

Devereux, Michael, Eric Young, and Changhua Yu, "A new dilemma: capital controls and monetary policy in Sudden Stop economies," 2015. NBER Working Paper No. 21791.

Diewert, Erwin and Kevin Fox, "On the estimation of returns to scale, technical progress and monopolistic markups," Journal of Econometrics, 2008, 145, 174-193.

Farhi, Emmanuel and Ivan Werning, "Dilemma not Trilemma? Capital Controls and Exchange Rates with Volatile Capital Flows," IMF Economic Review, 2014, 62 (4), 569-605.

_ and _. "A Theory of Macroprudential Policies in the Presence of Nominal Rigidities," Econometrica, 2016, 84, 1645-1704.

Fornaro, Luca, "Financial crises and exchange rate policy," Journal of International Economics, 2015, 95, 202-215.

Gali, Jordi and Tommaso Monacelli, "Monetary Policy and Exchange Rate Volatility in a Small Open Economy," Review of Economic Studies, 2005, 72, 707-734.

Gertler, Mark, Simon Gilchrist, and Fabio Natalucci, "External constraints on monetary policy and the financial accelerator," Journal of Money, Credit and Banking, 2007, 39 (2-3), 295-330.

Greenwood, Jeremy, Zvi Hercowitz, and Gregory Huffman, "Investment, capacity utilization, and the real business cycle," American Economic Review, 1988, 78, 402-417.

Jeanne, Olivier and Anton Korinek, "Managing credit booms and busts: A pigouvian taxation approach," 2012. manuscript.

Kaminsky, Graciela, Carmen Reinhart, and Carlos Vegh, "When It Rains, It Pours: Procyclical Capital Flows and Policies," 2004. NBER Working Paper No. w10780.

Kimball, Miles and Matthew Shapiro, "Labor supply: are the income and substitution effects both large or both small," 2008. NBER Working Paper No. 14208. 
Klein, Paul, Per Krussel, and Jose-Victor Rios-Rull, "Time-consistent public policy," Review of Economic Studies, 2008, 75, 789-808.

Kollmann, Robert, "Monetary policy rules in the open economy: effects on welfare and business cycles," Journal of Monetary Economy, 2002, 49 (5), 989-1015.

Korinek, Anton, "Regulating Capital Flows to Emerging Markets: An Externality View," 2009. Unpublished.

_, "The New Economics of Prudential Capital Controls: A Research Agenda," 2011. IMF Economic Review, International Monetary Fund.

Kydland, Finn and Edward Prescott, "Rules Rather than Discretion: The Inconsistency of Optimal Plans," Journal of Political Economy, 1977, 85 (3), 473-492.

Lorenzoni, Guido, "Inefficient Credit Booms," Review of Economic Studies, 2008, 75, 809833.

Lucas, Robert, "Expectations and the Neutrality of Money," Journal of Economic Theory, 1972, 4, 103-124.

Mendoza, Enrique, "Credit, prices, and crashes: business cycles with a sudden stop. Preventing Currency Crises in Emerging Markets," University of Chicago Press, 2002, pp. 335-392.

Moron, Edouardo and Diego Winkelried, "Monetary policy rules for financially vulnerable economies," Journal of Development Economics, 2005, 76 (1), 23-51.

Ottonello, Pablo, "Optimal Exchange-Rate Policy Under Collateral Constraints and Wage Rigidity," 2015. manuscript, University of Michigan.

Rey, Hélène, "Dilemma not Trilemma: The Global Financial Cycle and Monetary Policy Independence," 2015. NBER Working Paper No. 21162.

Rotemberg, Julio, "Sticky prices in the united states," Journal of Political Economy, 1982, 90, 1187-1211.

Schmitt-Grohé, Stephanie and Martin Uribe, "Optimal simple and implementable monetary and fiscal rules," Journal of Monetary Economy, 2007, 54, 1702-1725.

_ and _, "Downward Nominal Wage Rigidity, Currency Pegs, and Involuntary Unemployment," Journal of Political Economy, 2016, 124, 1466-1514. 
Tauchen, George and Robert Hussey, "Quadrature-based methods for obtaining approximate solutions to nonlinear asset pricing models," Econometrica, 1991, 59 (2), 371-396.

Woodford, Michael, "Interest and Prices: Foundations of a Theory of Monetary Policy," 2003. Princeton University Press. 


\section{Appendix}

\section{A Proofs}

The government's time-consistent problem in recursive form is rewritten here for convenience:

$$
\mathcal{V}(b, s)=\max _{c^{T}, \ell, b^{\prime}, p^{N}, \pi^{N}, \mu} u\left[c\left(c^{T}, c^{N}\right), \ell\right]+\beta \mathbb{E}_{s^{\prime} \mid s} \mathcal{V}\left(b^{\prime}, s^{\prime}\right)
$$

subject to

$$
\begin{aligned}
& c^{N}=\alpha\left(p^{N}\right) c^{T} \\
& c^{N}=\left[1-\frac{\varphi}{2}\left(\pi^{N}\right)^{2}\right] A \ell \\
& c^{T}=y^{T}+b-\frac{b^{\prime}}{R} \\
& \frac{b^{\prime}}{R} \geq-\kappa\left(y^{T}+p^{N} c^{N}\right) \\
& \mu=u_{T}(c, \ell)-\beta R \mathbb{E}_{s^{\prime} \mid s} u_{T}\left(\mathcal{C}\left(b^{\prime}, s^{\prime}\right), \mathcal{L}\left(b^{\prime}, s^{\prime}\right)\right) \\
& \mu \times\left[b^{\prime}+\kappa\left(y^{T}+p^{N} c^{N}\right)\right]=0 \\
& 0=\varphi \pi^{N}\left(1+\pi^{N}\right)+(\varepsilon-1)\left[1-z^{-1}(1-\omega)\right]-\varphi \ell^{-1} \mathbb{E}_{s^{\prime} \mid s} \Lambda\left[\mathcal{L}\left(b^{\prime}, s^{\prime}\right) \mathcal{M}\left(b^{\prime}, s^{\prime}\right)\right]
\end{aligned}
$$

Let $\iota \geq 0, \lambda^{*} \geq 0$ and $\mu^{*} \geq 0$ be the multiplier on the resource constraint for non-tradables, tradables and the credit constraint respectively; $\delta, v, \nu$ and $\xi$ be the multiplier on (A.2), (A.6)(A.8). I define an auxiliary variable: $\psi \equiv(\varepsilon-1)\left[1-z^{-1}(1-\omega)\right]-\varphi \ell^{-1} \mathbb{E}_{s^{\prime} \mid s} \Lambda\left[\mathcal{L}\left(b^{\prime}, s^{\prime}\right) \mathcal{M}\left(b^{\prime}, s^{\prime}\right)\right]$.

\section{A.1 Proof of Proposition 1}

In the absence of credit frictions, the government's optimisation problem reduces to solving (A.1) subject to (A.3), (A.4), (A.6) with equality $\mu_{t}=0$ and (A.8). The proof proceeds by

analyzing a relaxed problem where the government is not subject to (A.6) and then showing that this condition is satisfied. Abstracting from the implementability constraint (A.6), the government's optimality conditions, after eliminating the multiplier $\delta$ in the key equations, are:

$$
\begin{aligned}
c_{t}^{T}:: & \lambda_{t}^{*}=u_{T}(t)+\mu_{t}^{*} \gamma^{-1} \kappa \frac{p_{t}^{N} c_{t}^{N}}{c_{t}^{T}}+\xi_{t} \psi_{T, t} \\
b_{t+1}:: & \lambda_{t}^{*}=\beta R_{t} \mathbb{E}_{t} \lambda_{t+1}+\mu_{t}^{*}+\xi_{t} \psi_{b, t} \\
\ell_{t}+c_{t}^{N}:: & y_{t}^{N} u_{N}(t)\left(\omega_{t}-\frac{\varphi}{2}\left(\pi_{t}^{N}\right)^{2}\right)=\xi_{t}\left(-c_{t}^{N} \psi_{N, t}-\ell_{t} \psi_{\ell, t}\right) \\
\pi_{t}^{N}:: & \xi_{t}=\frac{\varphi \iota_{t} y_{t}^{N}}{1+2 \pi_{t}^{N}} \pi_{t}^{N}
\end{aligned}
$$


where the optimality condition (A.11) combines the first order condition with respect to labor and non-tradable consumption to eliminate the multiplier $\iota$.

Consider now a price stability policy, $\pi_{t}^{N}=0$ for all $t$. Under this policy, by equation (A.12), it follows that $\xi_{t}=0$. Substituting into (A.11) implies that $\omega_{t}=0$, and into (A.9) implies that $\lambda_{t}^{*}=u_{T}(t)$. Using the latter together with (A.10) leads to:

$$
u_{T}(t)=\beta R_{t} \mathbb{E}_{t} u_{T}(t+1) .
$$

The implementability constraint (A.6) is then satisfied. Therefore, a price stability policy is optimal and it stabilizes the economy (i.e. $\omega_{t}=0$ ).

\section{A.2 Proof of Proposition 2}

To characterize the optimal time-consistent monetary policy, I solve for the government's optimization problem (A.1) given that future path of the inflation rate $\mathcal{M}$ are chosen by future government with which are associated with policies $\{\mathcal{C}(b, s), \mathcal{L}(b, s), \mathcal{B}(b, s), \mathcal{V}(b, s)\}$.

The optimality conditions of the government problem (A.1), after eliminating the multiplier $\delta$ in the key equations, are given by:

$$
\begin{aligned}
c_{t}^{T}:: & \lambda_{t}^{*}=u_{T}(t)+\mu_{t}^{*} \gamma^{-1} \kappa \frac{p_{t}^{N} c_{t}^{N}}{c_{t}^{T}}-v_{t} u_{T T}(t)+\xi_{t} \psi_{T, t} \\
b_{t+1}:: & \lambda_{t}^{*}=\beta R_{t} \mathbb{E}_{t}\left(\lambda_{t+1}+v_{t} \frac{\partial u_{T}(t+1)}{\partial b_{t+1}}\right)+\mu_{t}^{*}+\xi_{t} \psi_{b, t} \\
\mu_{t}:: & v_{t}+\nu_{t}\left[b_{t+1}+\kappa\left(p_{t}^{N} y_{t}^{N}+y_{t}^{T}\right)\right]+\xi_{t}(\varepsilon-1)\left(1-\omega_{t}\right) z_{t}^{-2} \frac{\kappa}{u_{T}(t)}=0 \\
\ell_{t}+c_{t}^{N}:: & u_{N}(t) y_{t}^{N}\left(\omega_{t}-\frac{\varphi}{2}\left(\pi_{t}^{N}\right)^{2}\right)+\left(\sigma-\gamma^{-1}\right) \frac{c_{T}(t)}{c_{t}} c_{t}^{N} u_{N}(t) v_{t} \\
\pi_{t}^{N}:: & \left(1-\gamma^{-1}\right) \kappa p_{t}^{N} c_{t}^{N} \mu_{t}^{*}=\xi_{t}\left(-c_{t}^{N} \psi_{N, t}-\ell_{t} \psi_{\ell, t}\right) \\
& \xi_{t}=\frac{\varphi \iota_{t} y_{t}^{N}}{1+2 \pi_{t}^{N}} \pi_{t}^{N}
\end{aligned}
$$

where the optimality condition (A.16) combines the first order condition with respect to labor and non-tradable consumption to eliminate the multiplier $\iota$.

These expressions are obtained by assuming that the policies and value functions are differentiable, with $\tilde{\mu}_{t}^{*}=\mu_{t}^{*}+\nu_{t} \mu_{t}$ that represents the government's effective shadow value on the credit constraint. It can also be shown that $\tilde{\mu}_{t}^{*}=\mu_{t}^{*}$ for all $t$. To clearly see this, notice first that when the constraint does not binds (i.e. $\mu_{t}^{*}=0$ ), the implementability constraint (A.7) is always satisfied. Thus, setting $\nu_{t}$ to zero is optimal and it follows that $\tilde{\mu}_{t}^{*}=\mu_{t}^{*}=0$. When the constraint binds, the implementability constraint (A.7) implies that $\mu_{t}=0$ and again $\tilde{\mu}_{t}^{*}=\mu_{t}^{*}$. 
To simplify the notation, I define $\tilde{\iota}_{t} \equiv \iota_{t} /\left(1+2 \pi_{t}^{N}\right) u_{N}(t)$. Combining (A.16) with (A.17), using the definition of $\psi_{t}$, and rearranging the expression yields

$$
\varphi\left(\Delta_{0, t}+\frac{\pi_{t}^{N}}{2}\right) y_{t}^{N} \pi_{t}^{N}=y_{t}^{N} \omega_{t}+\varphi \mathbb{E}_{t}\left[\Delta_{1, t+1} \pi_{t+1}^{N}\right]+\left(\sigma-\gamma^{-1}\right) \frac{c_{T}(t)}{c_{t}} c_{t}^{N} v_{t}+\left(1-\gamma^{-1}\right) \kappa p_{t}^{N} c_{t}^{N} \frac{\mu_{t}^{*}}{u_{N}(t)}
$$

where

$$
\Delta_{0, t}=(\varepsilon-1) z_{t}^{-1} \tilde{\iota}_{t} \frac{-u_{\ell}(t)}{A u_{N}(t)}\left[\frac{\gamma^{-1} \kappa p_{t}^{N} \mu_{t}-c_{t}^{N} u_{N N}(t)}{z_{t} u_{N}(t)}+\ell_{t} \frac{u_{\ell \ell}(t)}{u_{\ell}(t)}\right]>0
$$

and

$$
\Delta_{1, t+1}=\left(1+\frac{c_{t}^{N} u_{N N}(t)}{u_{N}(t)}\right) \frac{\tilde{\iota}_{t}}{\ell_{t}} \Lambda_{t, t+1} \ell_{t+1}\left(1+\pi_{t+1}^{N}\right)
$$

The equilibrium under the discretionary monetary policy can be characterized by sequences $\left\{c_{t}^{T}, c_{t}^{N}, \ell_{t}, b_{t+1}, \mu_{t}, \pi_{t}^{N}, p_{t}^{N}\right\}_{t=0}^{\infty}$ that satisfy (4)-(8), (10), (11) along with the complementary slackness condition and (A.2).

\section{A.3 Proof of Proposition 3}

The proof proceeds by first showing that any allocation $\left\{c_{t}^{T}, \ell_{t}, b_{t+1}, p_{t}^{N}, \pi_{t}^{N}\right\}$ that satisfy (16)(18) and (21) also satisfy the general equilibrium, and then describing the optimal monetary policy and optimal tax rate.

Consider any allocation $\left\{c_{t}^{T}, \ell_{t}, b_{t+1}, p_{t}^{N}, \pi_{t}^{N}\right\}$ that satisfy (16)-(18) and (21). Then, set $c_{t}^{N}=$ $\left[1-\varphi\left(\pi_{t}^{N}\right)^{2}\right] A \ell_{t}$ and $\mu_{t}=0$ to satisfy (15) and (20) respectively. Choose $\tau_{t}^{b}=1-\beta R_{t} \frac{\mathbb{E}_{t} u_{T}(t+1)}{u_{(}(t)}$. By definition, this makes (26) hold also. The government's optimisation problem then reduces to

$$
\mathcal{V}(b, s)=\max _{c^{T}, \ell, b^{\prime}, p^{N}, \pi^{N}} u\left[c\left(c^{T}, \alpha\left(p^{N}\right) c^{T}\right), \ell\right]+\beta \mathbb{E}_{s^{\prime} \mid s} \mathcal{V}\left(b^{\prime}, s^{\prime}\right)
$$

subject to

$$
\begin{aligned}
& \alpha\left(p^{N}\right) c^{T}=\left[1-\frac{\varphi}{2}\left(\pi^{N}\right)^{2}\right] A \ell \\
& c^{T}=y^{T}+b-\frac{b^{\prime}}{R} \\
& \frac{b^{\prime}}{R} \geq-\kappa\left(p^{N} A \ell+y^{T}\right) \\
& \varphi \pi^{N}\left(1+\pi^{N}\right)+(\varepsilon-1) \omega-\varphi \ell^{-1} \mathbb{E}_{s^{\prime} \mid s} \Lambda\left[\mathcal{L}\left(b^{\prime}, s^{\prime}\right) \mathcal{M}\left(b^{\prime}, s^{\prime}\right)\right]=0
\end{aligned}
$$

Again $\iota \geq 0, \lambda^{*} \geq 0$ are the multiplier on the resource constraint for the nontradable good and the tradable good respectively, $\mu^{*} \geq 0$ is the multiplier on the credit constraint, $\xi \geq 0$ is the multiplier the nontradable good pricing implementability constraint. The optimality conditions 
of the government's problem, when capital flow taxes are available, are given by:

$$
\begin{aligned}
c_{t}^{T}:: & \lambda_{t}^{*}=u_{T}(t)+\mu_{t}^{*} \gamma^{-1} \kappa \frac{p_{t}^{N} c_{t}^{N}}{c_{t}^{T}}+\xi_{t} \psi_{T, t} \\
b_{t+1}:: & \lambda_{t}^{*}=\beta R_{t} \mathbb{E}_{t} \lambda_{t+1}^{*}+\mu_{t}^{*}+\xi_{t} \psi_{b^{\prime}, t} \\
c_{t}^{N}+\ell_{t}:: & y_{t}^{N} u_{N}(t)\left(\omega_{t}-\frac{\varphi}{2}\left(\pi_{t}^{N}\right)^{2}\right)+\left(1-\gamma^{-1}\right) \kappa p_{t}^{N} c_{t}^{N} \mu_{t}^{*}=\xi_{t}\left(-c_{t}^{N} \psi_{N, t}-\ell_{t} \psi_{\ell, t}\right) \\
\pi_{t}^{N}:: & \xi_{t}=\frac{\varphi \iota_{t} y_{t}^{N}}{1+2 \pi_{t}^{N}} \pi_{t}^{N}
\end{aligned}
$$

where the optimality condition (A.11) combines the first order condition with respect to labor and non-tradable consumption to eliminate the multiplier $\iota$.

Combining (A.21) with (A.22) and rearranging the expression yields

$$
\varphi\left(\Delta_{0, t}+\frac{\pi_{t}^{N}}{2}\right) \pi_{t}^{N}=y_{t}^{N} \omega_{t}+\varphi \mathbb{E}_{t}\left[\Delta_{1, t+1} \pi_{t+1}^{N}\right]+\left(1-\gamma^{-1}\right) \kappa p_{t}^{N} c_{t}^{N} \frac{\mu_{t}^{*}}{u_{N}(t)}
$$

This complete the proof that when taxes are available and used optimally, the path for the inflation rate when the government cannot commit to future policies satisfies (A.23) as in Proposition 3. The optimal tax rate is given by:

$$
\tau_{t}^{b}=\frac{\beta R_{t} \mathbb{E}_{t}\left[\Theta_{t+1} \mu_{t+1}^{*}+\xi_{t+1} \psi_{T, t+1}\right]-\Theta_{t} \mu_{t}^{*}-\xi_{t} \psi_{T, t}+\xi_{t} \psi_{b^{\prime}, t}}{\beta R_{t} \mathbb{E}_{t} u_{T}(t+1)}
$$

with $\Theta_{t}=(1 / \gamma) \kappa p_{t}^{N} c_{t}^{N} / c_{t}^{T}$. 


\section{B Alternatives Formulations}

\section{B.1 Nominal Interest Rate as Monetary Policy Instrument}

In this section, I assume that households have access, in addition to a one period non-statecontingent foreign bond, to a one period non-state-contingent domestic bond. The domestic bond is a one period non-state-contingent traded only among domestic households, and pays a net nominal interest rate $i_{t}$ determined by the central bank (government).

The representative household' problem can be re-written as

$$
\max _{c_{t}^{T}, c_{t}^{N}, \ell_{t}, b_{t+1}, b_{t+1}^{h}} \mathbb{E}_{0} \sum_{t=0}^{\infty} \beta^{t} u\left(c\left(c_{t}^{T}, c_{t}^{N}\right), \ell_{t}\right)
$$

subject to

$$
\begin{aligned}
P_{t}^{T} c_{t}^{T}+P_{t}^{N} c_{t}^{N}+\frac{\mathcal{E}_{t} b_{t+1}}{R_{t}}+\frac{b_{t+1}^{h}}{1+i_{t}} & =P_{t}^{T} y_{t}^{T}+W_{t} \ell_{t}+\Phi_{t}+\mathcal{E}_{t} b_{t}+b_{t}^{h} \\
\frac{\mathcal{E}_{t} b_{t+1}}{R_{t}} & \geq-\kappa\left[P_{t}^{T} y_{t}^{T}+W_{t} \ell_{t}+\Phi_{t}\right]
\end{aligned}
$$

where $b_{t+1}^{h}$ denote the household?s holdings of domestic and foreign bond respectively. Combining the optimality condition for both foreign bond and domestic bond, it follows that

$$
\beta \mathbb{E}_{t}\left[u_{T}(t+1)\left(\frac{\mathcal{E}_{t}}{\mathcal{E}_{t+1}}\left(1+i_{t}\right)-R_{t}\right)\right]=\mu_{t}
$$

It is important to observe that the net supply of domestic bond is equal to zero in equilibrium. Therefore, for any alloocation under the discretionary monetary policy described in the section 3 , the equation (B.1) can be used to back out the domestic nominal interest rate.

\section{B.2 GHH Preferences}

In this section, I derive the discretionary monetary policy in an environment in which households' preferences are specified following Greenwood et al. (1988), where utility is defined in terms of the excess of consumption over the disutility of labor. Formally, I assume

$$
u(c, \ell)=u(c-g(\ell))
$$

The disutility function $g(\cdot)$ is twice-continuously differentiable, strictly increasing and convex.

The discretionary monetary policy, with credit frictions and when capital flow taxes cannot 
be used, then solves

$$
\mathcal{V}(b, s)=\max _{c^{T}, c^{N}, \ell, b^{\prime}, p^{N}, \pi^{N}, \mu} u\left[c\left(c^{T}, c^{N}\right)-g(\ell)\right]+\beta \mathbb{E}_{s^{\prime} \mid s} \mathcal{V}\left(b^{\prime}, s^{\prime}\right)
$$

subject to (A.2), (A.3), (A.4), (A.5), (A.6), (A.7), (A.8)

Solving this problem, and following the same procedure as in appendix A.2, it can be shown that the path of the inflation rate under the discretionary monetary policy satisfies:

$$
\begin{aligned}
\varphi\left(\Delta_{0, t}+\frac{\pi_{t}^{N}}{2}\right) \pi_{t}^{N}= & y_{t}^{N} \omega_{t}+\varphi \mathbb{E}_{t}\left[\Delta_{1, t+1} \pi_{t+1}^{N}\right] \\
& +\left(\left(\sigma-\gamma^{-1}\right) \frac{c_{T}(t)}{c_{t}} c_{t}^{N}+\sigma \frac{\ell_{t} g^{\prime}\left(\ell_{t}\right)}{p_{t}^{N} c_{t}}\right) v_{t}+\left(1-\gamma^{-1}\right) \kappa p_{t}^{N} c_{t}^{N} \frac{\mu_{t}^{*}}{u_{N}(t)}
\end{aligned}
$$

where the expression for $\Delta_{0, t}>0$ is also given by (A.18). It straightforward to see that the discretionary monetary policy is procyclical for $1 / \sigma<\gamma<1$. An interesting feature of the GHH preferences is that it amplifies the effect of overborrowing during tranquil times. 


\section{Numerical Solution Method (Algorithm)}

\section{C.1 For Competitive Equilibrium under a Price Stability Policy}

This algorithm is build on Bianchi (2011)'s algorithm that incorporates the occasionally binding endogenous constraint, modified to account for the nominal rigidities. Formally, the computation of the competitive equilibrium operates directly on the first-order conditions and requires solving for functions $\left\{\mathcal{B}(b, s), \mathcal{L}(b, s), \mathcal{C}^{T}(b, s), \mathcal{P}^{N}(b, s), \mu(b, s)\right\}$ such that:

$$
\begin{aligned}
& \mathcal{C}^{T}(b, s)+\frac{\mathcal{B}(b, s)}{R}=y^{T}+b \\
& \alpha\left(\mathcal{P}^{N}(b, s)\right) \mathcal{C}^{T}(b, s)=A \mathcal{L}(b, s) \\
& \frac{\mathcal{B}(b, s)}{R} \geq-\kappa\left(A \mathcal{P}^{N}(b, s) \mathcal{L}(b, s)+y^{T}\right) \\
& u_{T}(c(b, s)-g(\mathcal{L}(b, s))) \\
& \quad=\beta R \mathbb{E}_{s^{\prime} \mid s}\left\{u_{T}\left(c\left(\mathcal{B}(b, s), s^{\prime}\right)-g(\mathcal{L}(\mathcal{B}(b, s), s))\right)\right\}+\mu(b, s) \\
& u_{N}(c(b, s)-g(\mathcal{L}(b, s)))+\frac{1}{A} u_{\ell}(c(b, s)-g(\mathcal{L}(b, s)))=-\kappa \mathcal{P}^{N}(b, s) \mu(b, s)
\end{aligned}
$$

where $c(b, s) \equiv c\left(\mathcal{C}^{T}(b, s), A \mathcal{L}(b, s)\right)$. The steps for the algorithm are the following:

1. Generate discrete grids $G_{b}=\left\{b_{1}, b_{2}, \ldots, b_{M}\right\}$ for the bond position and $G_{s}=\left\{s_{1}, s_{2}, \ldots, s_{N}\right\}$ for the shock state space, and choose an interpolation scheme for evaluating the functions outside the grid of bonds. The piecewise linear approximation is used to interpolate the functions and the grid for bonds contains 200 points.

2. Conjecture $\mathcal{B}_{h}(b, s), \mathcal{L}_{h}(b, s), \mathcal{C}_{h}^{T}(b, s), \mathcal{P}_{h}^{N}(b, s), \mu_{h}(b, s)$ at time $H, \forall b \in G_{b}$ and $\forall s \in G_{s}$.

3. Set $i=1$

4. Solve for the values of $\mathcal{B}_{h-i}(b, s), \mathcal{L}_{h-i}(b, s), \mathcal{C}_{h-i}^{T}(b, s), \mathcal{P}_{h-i}^{N}(b, s), \mu_{h-i}(b, s)$ at time $h-i$ using (C.1)-(C.5) and $\mathcal{B}_{h-i+1}(b, s), \mathcal{L}_{h-i+1}(b, s), \mathcal{C}_{h-i+1}^{T}(b, s), \forall b \in G_{b}$ and $\forall s \in G_{s}$ :

(a) First, assume that the credit constraint (C.3) is not binding. Set $\mu_{h-i}(b, s)=0$ and using (C.4), (C.5) and a root finding algorithm solve for $\mathcal{C}_{h-i}^{T}(b, s)$ and $\mathcal{L}_{h-i}(b, s)$. Solve for $\mathcal{B}_{h-i}(b, s)$ and $\mathcal{P}_{h-i}^{N}(b, s)$ using (C.1) and (C.2).

(b) Check whether $\frac{\mathcal{B}_{h-i}(b, s)}{R} \geq-\kappa\left(A \mathcal{P}_{h-i}^{N}(b, s) \mathcal{L}_{h-i}(b, s)+y^{T}\right)$ holds. If the credit constraint is satisfied, move to the next grid point.

(c) Otherwise, using (C.1), (C.3), (C.4), (C.5) and a root finding algorithm solve for $\mu_{h-i}(b, s), \mathcal{B}_{h-i}(b, s), \mathcal{C}_{h-i}^{T}(b, s)$ and $\mathcal{L}_{h-i}(b, s)$ and using (C.2) solve for $\mathcal{P}_{h-i}^{N}(b, s)$. 
5. Convergence. The competitive equilibrium is found if $\left\|\sup _{B, s} x_{h-i}(b, s)-x_{h-i+1}(b, s)<\epsilon\right\|$ for $x \in\left\{\mathcal{B},, \mathcal{L}, \mathcal{C}^{T}\right\}$. Otherwise, set $x_{h-i}(b, s)=x_{h-i+1}(b, s), i \approx i+1$ and go to step 4 .

\section{C.2 For Optimal Time-Consistent Monetary Policy}

The solution method proposed here uses a nested fixed point algorithm to solve for optimal time-consistent monetary policy and is related to the literature using Markov perfect equilibria (e.g. Klein et al. (2008) and Bianchi and Mendoza (2018)). In the inner loop, using the Bellman equation and value function iteration, solve for value function and policy functions taking as given future policies. Formally, given functions $\left\{\mathcal{C}^{T}(b, s), \mathcal{P}^{N}(b, s), \mathcal{B}(b, s), \mathcal{L}(b, s), \mathcal{M}(b, s)\right\}$, the Bellman equation is given by:

$$
\begin{gathered}
\mathcal{V}(b, s)=\max _{c^{T}, \ell, b^{\prime}, p^{N}, \pi^{N}, \mu} u\left[c\left(c^{T}, \alpha\left(p^{N}\right) c^{T}\right)-g(\ell)\right]+\beta \mathbb{E}_{s^{\prime} \mid s} \mathcal{V}\left(b^{\prime}, s^{\prime}\right) \\
\text { s.t. } \quad \alpha\left(p^{N}\right) c^{T}=\left[1-\frac{\varphi}{2}\left(\pi^{N}\right)^{2}\right] A \ell \\
c^{T}=y^{T}+b-\frac{b^{\prime}}{R} \\
\quad \frac{b^{\prime}}{R} \geq-\kappa\left(p^{N} A \ell+y^{T}\right) \\
\mu=u_{T}(c, \ell)-\beta R \mathbb{E}_{s^{\prime} \mid s} u_{T}\left(c\left(\mathcal{C}^{T}\left(b^{\prime}, s^{\prime}\right), \mathcal{P}^{N}\left(b^{\prime}, s^{\prime}\right)\right)-g\left(\mathcal{L}\left(b^{\prime}, s^{\prime}\right)\right)\right) \\
\mu \times\left[b^{\prime}+\kappa\left(p^{N} A \ell+y^{T}\right)\right]=0 \\
\varphi \pi^{N}\left(1+\pi^{N}\right)-(\epsilon-1)\left[z^{-1}(1-\omega)-1\right]-\varphi \ell^{-1} \mathbb{E}_{s^{\prime} \mid s} \Lambda\left[\mathcal{L}\left(b^{\prime}, s^{\prime}\right) \mathcal{M}\left(b^{\prime}, s^{\prime}\right)\right]=0
\end{gathered}
$$

Given the solution to the Bellman equation, update future policies as the outer loop. The steps for the algorithm are the following:

1. Generate discrete grids $G_{b}=\left\{b_{1}, b_{2}, \ldots, b_{M}\right\}$ for the bond position and $G_{s}=\left\{s_{1}, s_{2}, \ldots, s_{N}\right\}$ for the shock state space, and choose an interpolation scheme for evaluating the functions outside the grid of bonds. The piecewise linear approximation is used to interpolate the functions and the grid for bonds contains 200 points.

2. Guess policy functions $\mathcal{B}, \mathcal{C}^{T}, \mathcal{P}^{N}, \mathcal{M}$ at time $H, \forall b \in G_{b}$ and $\forall s \in G_{s}$.

3. For given $\mathcal{L}, \mathcal{C}^{T}, \mathcal{P}^{N}, \mathcal{M}$ solve the recursive problem using value function iteration to find the value function and policy functions:

(a) First, assume that the credit constraint (C.9) is not binding. Set $\mu=0-$ (C.11) is thus satisfied - and solve the optimization problem (C.6) subject to (C.7), (C.8), (C.10), (C.12) using a Newton type algorithm and check whether (C.9) holds. 
(b) Second, assume that the credit constraint (C.9) is binding - (C.11) is thus satisfied. Solve the optimization problem (C.6) subject to (C.7)-(C.10), (C.12) using a Newton type algorithm.

(c) Compare the solutions in (a) and (b). The optimal choices in each state is the best solution. Denote $\left\{\nu^{i}\right\}_{i}$, with $i \in\left\{b^{\prime}, \ell, c^{T}, p^{N}, \pi^{N}\right\}$, the associated policy functions.

4. Evaluate convergence. Compute the sup distance between $\mathcal{B}, \mathcal{C}^{T}, \mathcal{P}^{N}, \mathcal{M}$ and $\left\{\nu^{i}\right\}$, with $i \in\left\{b^{\prime}, c^{T}, p^{N}, \pi^{N}\right\}$. If the sup distance is not smaller enough (higher than $\epsilon=1 e-7$ ), update $\mathcal{B}, \mathcal{C}^{T}, \mathcal{P}^{N}, \mathcal{M}$ and solve again the recursive problem. 